Article

\title{
Coating-Dependent Neurotoxicity of Silver Nanoparticles-An In Vivo Study on Hippocampal Oxidative Stress and Neurosteroids
}

\author{
Katarzyna Dziendzikowska ${ }^{1, *(\mathbb{D})}$, Jacek Wilczak ${ }^{2}\left(\mathbb{D}\right.$, Wojciech Grodzicki $^{1}$, Joanna Gromadzka-Ostrowska ${ }^{1}{ }^{1}$, \\ Małgorzata Węsierska ${ }^{3}$ and Marcin Kruszewski ${ }^{4,5}$
}

1 Department of Dietetics, Institute of Human Nutrition Sciences, Warsaw University of Life Sciences-SGGW, Nowoursynowska 159C, 02-776 Warsaw, Poland; wojciech_grodzicki@sgge.edu.pl (W.G.); joanna_gromadzka_ostrowska@sggw.edu.pl (J.G.-O.)

2 Department of Physiological Sciences, Institute of Veterinary Medicine, Warsaw University of Life Sciences, Nowoursynowska 159, 02-776 Warsaw, Poland; jacek_wilczak@sggw.edu.pl

3 Laboratory of Neuropsychology, Nencki Institute of Experimental Biology, Polish Academy of Sciences, 3 Pasteur Street, 02-093 Warsaw, Poland; m.wesierska@nencki.edu.pl

4 Centre for Radiobiology and Biological Dosimetry, Institute of Nuclear Chemistry and Technology, Dorodna 16, 03-195 Warsaw, Poland; m.kruszewski@ichtj.waw.pl

5 Department of Molecular Biology and Translational Research, Institute of Rural Health, Jaczewskiego 2, 20-090 Lublin, Poland

* Correspondence: katarzyna_dziendzikowska@sggw.edu.pl

Citation: Dziendzikowska, K.;

Wilczak, J.; Grodzicki, W.;

Gromadzka-Ostrowska, J.;

Węsierska, M.; Kruszewski, M. Coating-Dependent Neurotoxicity of Silver Nanoparticles-An In Vivo Study on Hippocampal Oxidative Stress and Neurosteroids. Int. J. Mol. Sci. 2022, 23, 1365. https://doi.org/ $10.3390 /$ ijms23031365

Academic Editors: Francesca Gelfo, Debora Cutuli and Laura Petrosini

Received: 30 December 2021

Accepted: 22 January 2022

Published: 25 January 2022

Publisher's Note: MDPI stays neutral with regard to jurisdictional claims in published maps and institutional affiliations.

Copyright: (C) 2022 by the authors. Licensee MDPI, Basel, Switzerland. This article is an open access article distributed under the terms and conditions of the Creative Commons Attribution (CC BY) license (https:// creativecommons.org/licenses/by/ $4.0 /)$.

\begin{abstract}
Silver nanoparticles (AgNPs) are one of the most widely used nanomaterials. The level of exposure to nanosilver is constantly raising, and a growing body of research highlights that it is harmful to the health, especially the nervous system, of humans. The potential pathways through which nanosilver affects neurons include the release of silver ions and the associated induction of oxidative stress. To better understand the mechanisms underlying the neurotoxicity of nanosilver, in this study we exposed male Wistar rats to $0.5 \mathrm{mg} / \mathrm{kg}$ body weight of AgNPs coated with bovine serum albumin (BSA), polyethylene glycol (PEG), or citrate, or to $\mathrm{AgNO}_{3}$ as a source of silver ions for 28 days and assessed the expression of antioxidant defense markers in the hippocampus of the exposed animals after 1 week of spatial memory training. We also evaluated the influence of AgNPs coating on neurosteroidogenesis in the rat hippocampus. The results showed that AgNPs disrupted the antioxidant system in the hippocampus and induced oxidative stress in a coating-dependent manner, which could potentially be responsible for neurodegeneration and cognitive disorders. The analysis of the influence of AgNPs on neurosteroids also indicated coating-dependent modulation of steroid levels with a significant decrease in the concentrations of progesterone and $17 \alpha$-progesterone in $\mathrm{AgNPs}(\mathrm{BSA}), \mathrm{AgNPs}(\mathrm{PEG})$, and $\mathrm{Ag}^{+}$groups. Furthermore, exposure to $\mathrm{AgNPs}$ or $\mathrm{Ag}^{+}$resulted in the downregulation of selected genes involved in antioxidant defense (Cat), neurosteroid synthesis (Star, Hsd3b3, Hsd17b1, and Hsd17b10), and steroid metabolism (Ar, Er1, and Er2). In conclusion, depending on the coating material used for their stabilization, AgNPs induced oxidative stress and modulated the concentrations of steroids as well as the expression of genes involved in steroid synthesis and metabolism.
\end{abstract}

Keywords: silver nanoparticles; nanoparticle coating; hippocampus; neurosteroids; oxidative stress; antioxidative defense

\section{Introduction}

The beginning of the 21st century saw rapid development of nanotechnology in almost every branch of modern science and technology, facilitating its use in a wide range of commercially available products [1]. The nanomaterial most commonly found in consumer products is nanosilver according to the Nanodatabase [2]. Due to their desirable physicochemical properties, antimicrobial effect, and ease of synthesis, silver nanoparticles 
(AgNPs) have been successfully applied in hygiene products, cosmetics, textiles, toys, food containers, and dietary supplements [1,3]. However, the widespread use of AgNPs has increased the level of human exposure to these nanomaterials, mainly by inhalation, dermal contact, and ingestion [4]. Numerous studies in recent years have shown that AgNPs elicit toxic effects in various tissues, including the nervous system [5-8], which raises legitimate concerns about their possible impact on human health.

As proven by in vitro experiments, nanosilver is capable of penetrating the cells of organisms and can be detected in high amounts in cytosol, endosomes, and lysosomes [9]. In human cell lines, exposure to AgNPs results in cytotoxicity and DNA damage, while in animal models nanosilver can affect multiple organs, cause reproductive system dysfunction, and alter brain functions [10-13]. Given the crucial role of the nervous system in the regulation of key vital functions, the neurotoxic potential of AgNPs has received special attention among researchers. In fact, nanoparticulate silver can cross the blood-brain barrier and accumulate in the brain, with an exceptionally slow excretion rate [14]. The presence of AgNPs in the nervous tissue has been linked to several adverse effects, such as decreased learning capacity and worsened social activity, indicating the disruption of hippocampal functions $[15,16]$.

One of the principal mechanisms through which nanomaterials exert toxicity is oxidative stress [17]. Nanosilver increases the formation of reactive oxygen species (ROS) and thus contributes to the depletion of antioxidant defense capacity, alterations in gene expression, inflammation, impairment of mitochondrial functions, DNA damage, and eventually, neuronal death $[11,13,18]$. In addition, nanosilver can promote detrimental processes, such as the formation of amyloid-beta plaques, which is observed in Alzheimer's disease, and may be a risk factor for neurodegeneration [18,19].

The toxicity of AgNPs is determined by several factors, such as the "Trojan horse effect" which involves the intracellular release of reactive silver ions. However, nanoparticles may themselves exhibit toxic potential, which is at least partially influenced by the type of surface coating used for their stabilization [11]. The functionalization of AgNPs has an impact on their bioavailability and interactions with plasma proteins. Under physiological conditions, plasma proteins adsorb on the surface of nanoparticles, forming a protein corona. The chemical composition of coating that enables the adsorption of different proteins determines the interaction of AgNPs with cells, and consequently, the fate of these nanoparticles in the exposed organism $[1,20]$. However, the mechanisms by which different surface modifications influence the neurotoxicity of nanosilver remain largely unknown.

Considering the extensive application of nanosilver in consumer products and increased human exposure, in this study we investigated the neurotoxic impact of AgNPs by analyzing the effects of differently coated AgNPs on the antioxidant parameters, oxidative stress, and neurosteroid metabolism in the hippocampus of orally exposed rats after 1 week of memory training.

\section{Results}

\subsection{Neurosteroid Level in the Hippocampus}

The results of ANOVA revealed that the concentrations of all neurosteroids in the rat hippocampus were significantly influenced by AgNPs depending on the type of coating used on the nanoparticles. The hippocampal concentration of pregnenolone did not significantly differ between the groups exposed to AgNPs with different types of coating, the $\mathrm{Ag}^{+}$group, and the control group (Ctrl) (Figure 1A). However, the level of pregnenolone was found to be significantly lower in the rats from the $\mathrm{Ag}^{+}$group compared to AgNPs coated with polyethylene glycol (PEG) and citrate (Cit) groups (ANOVA: $p=0.003$; post hoc: $p<0.001$ and $p<0.05$, respectively).

The hippocampal concentration of progesterone was significantly decreased in AgNPs

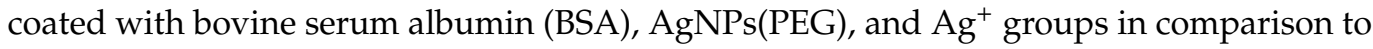
the control group (ANOVA: $p=0.001$; post hoc: $p<0.001, p<0.001$, and $p<0.05$, respectively) (Figure 1B). A similar relationship was observed in the case of $17 \alpha$-progesterone, the 
hippocampal concentration of which was found to be lower in $\mathrm{AgNPs}(\mathrm{Cit}), \mathrm{AgNPs}(\mathrm{BSA})$, and $\mathrm{Ag}^{+}$groups in comparison to the control group (ANOVA: $p=0.001$; post hoc: $p<0.001$, $p<0.001$, and $p<0.05$, respectively) (Figure 1C). On the other hand, the hippocampal concentration of allopregnanolone was the highest in the rats from the AgNPs(BSA) group and significantly higher compared to the control group (ANOVA: $p=0.001$; post hoc: $p<0.05$ ). Additionally, the level of allopregnanolone in $\mathrm{AgNPs}(\mathrm{BSA})$ and $\mathrm{AgNPs}(\mathrm{PEG})$ groups was observed to be significantly increased compared to the rats in $\mathrm{AgNPs}(\mathrm{Cit})$ and $\mathrm{Ag}^{+}$groups (post hoc: $p<0.001$ for all comparisons) (Figure 1D).
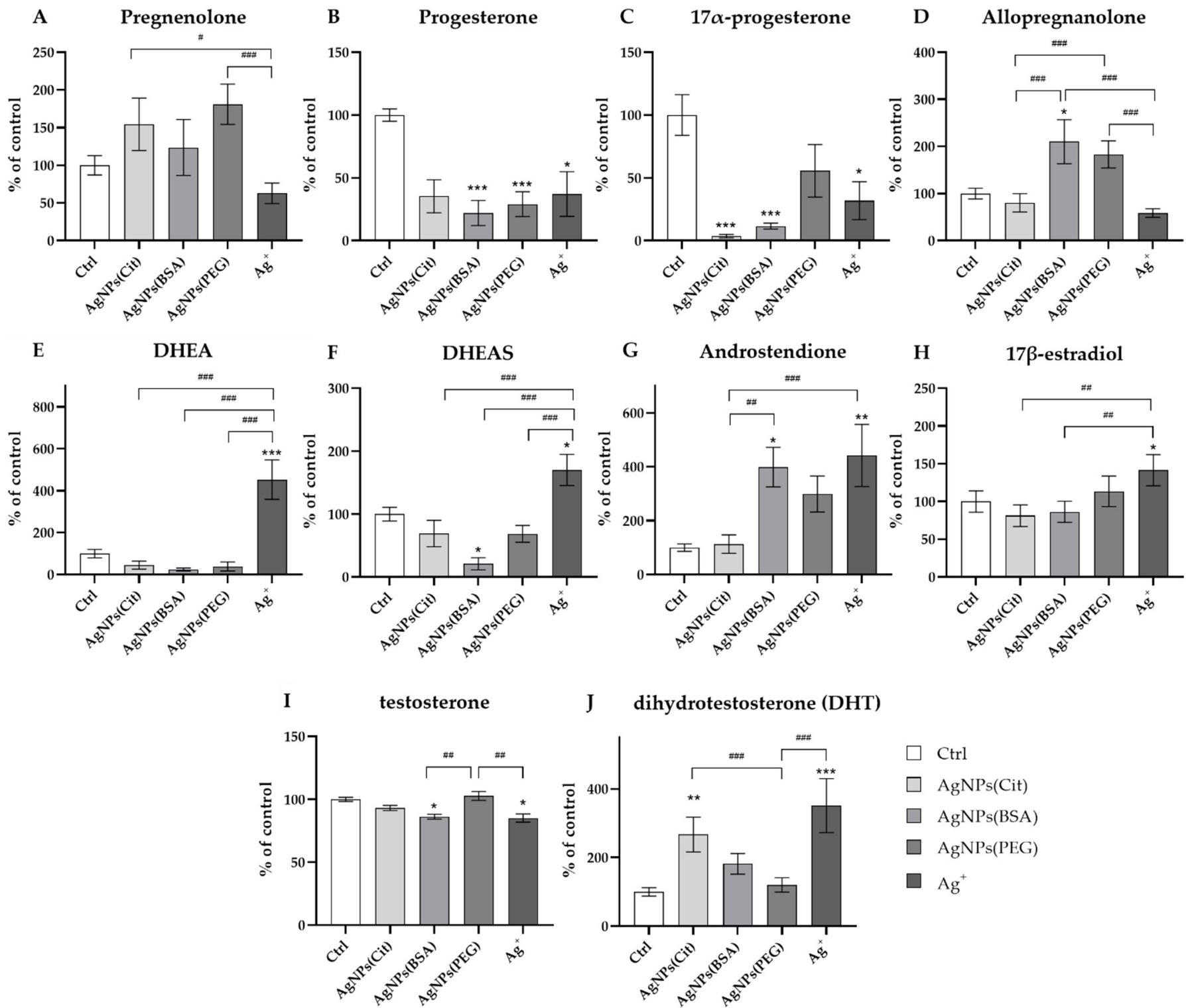

\section{J dihydrotestosterone (DHT)}
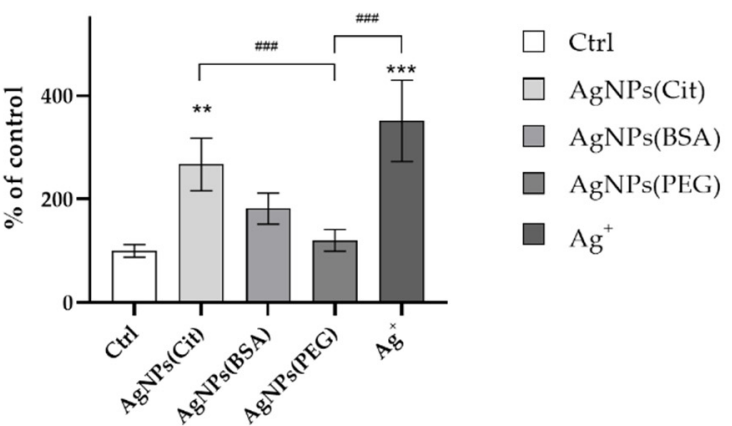

Figure 1. Neurosteroid levels in the hippocampus of rats exposed to AgNPs with different types of coating (citrate, bovine serum albumin (BSA) and polyethylene glycol (PEG)) or $\mathrm{Ag}^{+}: \quad$ (A)-pregnenolone; (B)-progesterone; (C)—17 $\alpha$-progesterone; (D)—allopregnanolone; (E)—dehydroepiandrosterone (DHEA); (F)—dehydroepiandrosterone sulfate (DHEAS); (G) —androstenedione; (H) — 17 $\beta$-estradiol; (I) — testosterone; (J)—dihydrotestosterone (DHT). Data are expressed as mean \pm SEM. ${ }^{* * * * * *}$ Significantly different from the control group

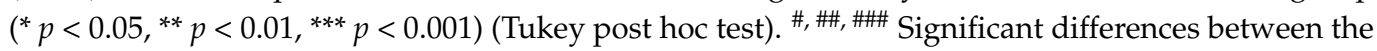
groups exposed to AgNPs or $\mathrm{Ag}^{+}\left({ }^{\#} p<0.05,{ }^{\# \#} p<0.01,{ }^{\# \#} p<0.001\right)$ (Tukey post hoc test). 
The hippocampal concentrations of two pregnenolone metabolites, dehydroepiandrosterone (DHEA) and dehydroepiandrosterone sulfate (DHEAS), which are formed in different biotransformation pathways, were the highest in the $\mathrm{Ag}^{+}$group (ANOVA: $p=0.001$ for both cases). The levels of these two metabolites found in the $\mathrm{Ag}^{+}$group significantly differed from those observed in the control group (post hoc: $p<0.001$ and $p<0.05$, respectively) and in all AgNPs-exposed animals (post hoc: $p<0.001$ for all comparisons) (Figure 1E (DHEA) and Figure 1F (DHEAS)).

The concentrations of two metabolites of progesterone-androstenedione and $17 \beta$ estradiol -were also found to be the highest in the rats from the $\mathrm{Ag}^{+}$group (ANOVA: $p=0.001$ for both steroids). The hippocampal levels of both androstenedione and $17 \beta$-estradiol in this group significantly differed from the concentration noted in the control group (post hoc: $p<0.01$ and $p<0.05$, respectively). Moreover, androstenedione concentration in the rats exposed to AgNPs(BSA) was significantly higher than that in the control animals (post hoc: $p<0.05)$ (Figure 1G (androstenedione) and Figure 1H (17 $\beta$-estradiol)). Additionally, the level of this neurosteroid was significantly higher in $\mathrm{Ag}^{+}$and $\mathrm{AgNPs}(\mathrm{BSA})$ groups in comparison to the $\operatorname{AgNPs}(\mathrm{Cit})$ group (post hoc: $p<0.001$ and $p<0.05$, respectively). The concentration of $17 \beta$-estradiol was also higher in $\mathrm{Ag}^{+}$rats than in $\mathrm{AgNPs}(\mathrm{BSA})$ and AgNPs(Cit) groups (post hoc: $p<0.01$ for both cases).

In addition, the concentration of two neurosteroids belonging to the androgens grouptestosterone and dihydrotestosterone (DHT) - differed depending on the type of nanosilver coating (ANOVA: $p=0.001$ for both androgens). A lower hippocampal concentration of testosterone was observed in the $\mathrm{Ag}^{+}$group compared to $\mathrm{AgNPs}(\mathrm{BSA})$ and $\mathrm{AgNPs}(\mathrm{Cit})$ animals (post hoc: $p<0.01$ for both comparisons) (Figure 1I). Interestingly, the hippocampal level of DHT was higher in the rats from $\mathrm{Ag}^{+}$and $\mathrm{AgNPs}(\mathrm{Cit})$ groups compared to that in the animals from the control group (post hoc: $p<0.001$ and $p<0.01$, respectively) as well as from the $\mathrm{AgNPs}(\mathrm{PEG})$ group (post hoc: $p<0.001$ for both comparisons) (Figure 1J).

\subsection{Antioxidant Potential and Oxidative Stress in the Hippocampus}

The statistical analysis revealed that the hippocampal activity of antioxidative enzymes was significantly influenced by AgNPs depending on the type of coating used. ANOVA indicated that different types of nanosilver coating showed different effects on the superoxide dismutase (SOD) activity in the hippocampus (ANOVA: $p=0.001$ ) (Figure 2A). The post hoc test revealed statistically higher SOD activity in $\operatorname{AgNPs}(\mathrm{BSA})$ and AgNPs(PEG) groups than the control group (post hoc: $p<0.001$ for both comparisons). Furthermore, significantly higher SOD activity was found in the AgNPs(BSA) group as compared to the $\mathrm{Ag}^{+}$group (post hoc: $p<0.01$ ). Similarly, the rats in the AgNPs(PEG) group exhibited an increased SOD activity in comparison to the animals in both $\mathrm{Ag}^{+}$and $\mathrm{AgNPs}(\mathrm{Cit})$ groups (post hoc: $p<0.001$ and $p<0.05$, respectively).

The values of glutathione reductase (GSR) activity determined in the studied groups are presented in Figure 2B. The statistical analysis showed that GSR activity in rats was affected by silver administration (ANOVA: $p=0.008$ ). Although no differences in GSR activity were found with regard to the control group, the post hoc test revealed that the GSR activity was significantly lower in the $\mathrm{Ag}^{+}$group in comparison to the animals receiving either AgNPs(BSA) or AgNPs(PEG) (post hoc: $p<0.05$ and $p<0.01$, respectively).

Glutathione peroxidase (GPx) activity was also significantly influenced by treatment with silver (ANOVA: $p=0.001$ ) (Figure 2C). As the post hoc test showed, GPx activity was significantly higher in the AgNPs(Cit), AgNPs(BSA), and $\mathrm{Ag}^{+}$groups (post hoc: $p<0.01$, $p<0.05$, and $p<0.01$, respectively) compared to that in the control group. In addition, the post hoc analysis revealed intergroup differences. Rats treated with AgNPs(PEG) displayed significantly lower GPx activity than the animals in the AgNPs(Cit) group, as well as those in $\mathrm{AgNPs}$ (BSA) and $\mathrm{Ag}^{+}$groups (post hoc: $p<0.01, p<0.05$, and $p<0.05$, respectively).

The total antioxidant status (TAS) values measured to assess the overall antioxidant status of the hippocampus in the studied groups are presented in Figure 2D. Although ANOVA revealed that the TAS level in the hippocampus was influenced by exposure 
to silver (ANOVA: $p=0.006$ ), the post hoc test indicated that only animals treated with AgNPs(BSA) showed significantly different TAS values from the other Ag-exposed groups, that is, $\operatorname{AgNPs}(\mathrm{PEG}), \mathrm{AgNPs} \mathrm{Cit})$, and $\mathrm{Ag}^{+}$groups (post hoc: $p<0.05$ for all comparisons).

A

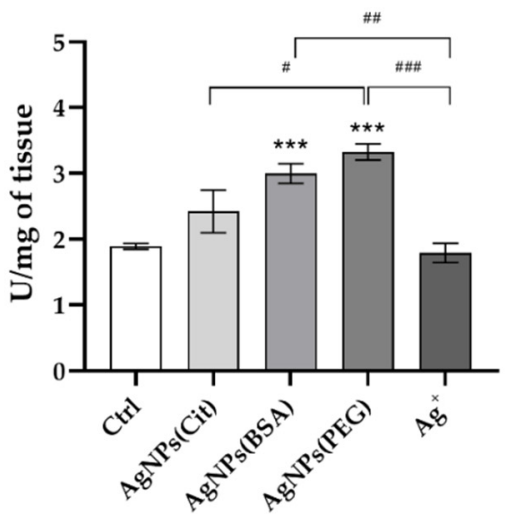

C

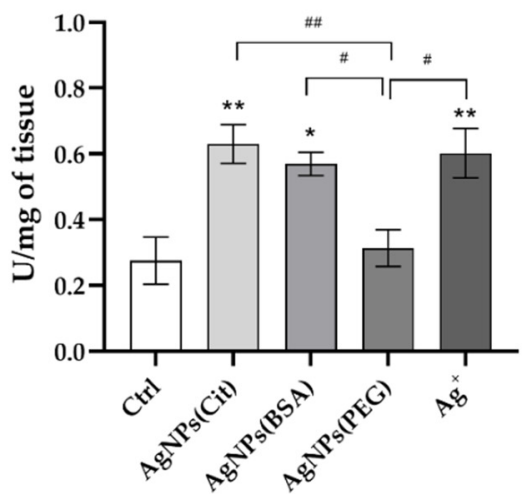

B

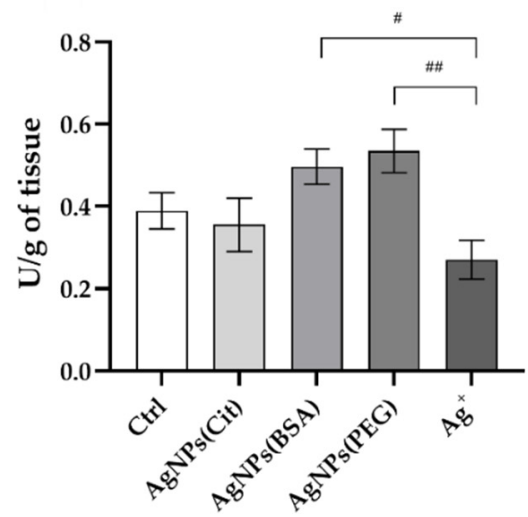

TAS

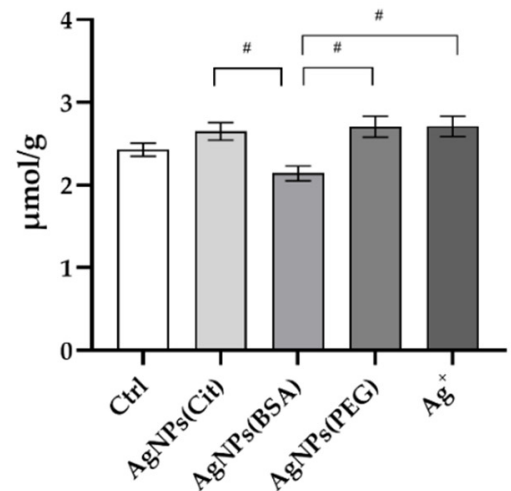

E

TBARS

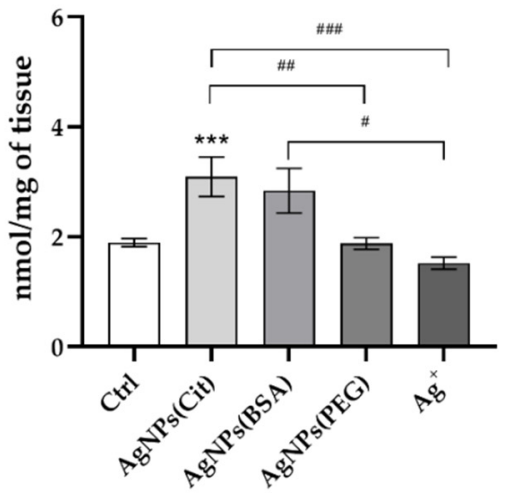
Ctrl
$\operatorname{AgNPs}(\mathrm{Cit})$
$\square \operatorname{AgNPs}(B S A)$
$\square \operatorname{AgNPs}(\mathrm{PEG})$
$\square \mathrm{Ag}^{+}$

Figure 2. Antioxidant potential and oxidative stress in the hippocampus of rats exposed to AgNPs with different types of coating (citrate, bovine serum albumin (BSA), and polyethylene glycol (PEG)) or $\mathrm{Ag}^{+}$: (A)—superoxide dismutase (SOD); (B)—glutathione reductase (GSR); (C)—glutathione peroxidase (GPx); (D)—total antioxidant status (TAS); (E)—thiobarbituric acid-reactive substances (TBARS). Data are expressed as mean \pm SEM. $* * * * * *$ Significantly different from the control group $\left({ }^{*} p<0.05,{ }^{* *} p<0.01,{ }^{* * *} p<0.001\right)$ (Tukey post hoc test). ${ }^{*}, \# \#, \# \#$ Significant differences between the groups exposed to AgNPs or $\mathrm{Ag}^{+}\left({ }^{\#} p<0.05,{ }^{\# \#} p<0.01,{ }^{\# \#} p<0.001\right)$ (Tukey post hoc test).

The results of the analysis of lipid peroxidation, which are expressed as the concentration of thiobarbituric acid-reactive substances (TBARS), are presented in Figure 2E. The 
TBARS levels in the studied groups were also influenced by silver administration (ANOVA: $p=0.001)$. Statistically significantly higher TBARS concentration was found in the control group and the $\operatorname{AgNPs}(\mathrm{Cit})$ group (post hoc: $p<0.01)$. AgNPs(BSA) treatment resulted in a significantly higher TBARS concentration in comparison to $\mathrm{Ag}^{+}$(post hoc: $p<0.05$ ). Similarly, $\operatorname{AgNPs}(\mathrm{Cit})$ treatment resulted in much higher lipid peroxidation level than AgNPs(PEG) and $\mathrm{Ag}^{+}$(post hoc: $p<0.01$ and $p<0.001$, respectively).

\subsection{Gene Expression Analysis}

The results of the analysis of antioxidant defense genes expression are shown in Table 1. Oral administration of $0.5 \mathrm{mg} / \mathrm{kg}$ b.w. of AgNPs with different types of coating or $\mathrm{Ag}^{+}$ for 28 days influenced the expression of the analyzed antioxidant defense/oxidative stress marker genes. According to ANOVA, catalase (Cat) expression was strongly influenced by silver (ANOVA: $p=0.006$ ), with statistically significant downregulation observed in AgNPs (PEG)- and $\mathrm{Ag}^{+}$-treated animals (post hoc: $p<0.05$ and $p<0.01$, respectively). Similarly, glutathione reductase (Gsr) gene expression was downregulated in $\mathrm{Ag}^{+}$-treated group (ANOVA: $p=0.047$, post hoc: $p<0.05$ ). No statistically significant differences in the expression of superoxide dismutase 1 (Sod1), superoxide dismutase 2 (Sod2), glutathione peroxidase 1 (Gpx1), and heme oxygenase 1 (Hmox1) genes were found between the experimental groups or between the experimental groups and the control group.

Table 1. Effect of oral administration of AgNPs with different types of coating (citrate, bovine serum albumin (BSA) and polyethylene glycol (PEG)) or $\mathrm{Ag}^{+}:(0.5 \mathrm{mg} / \mathrm{kg}$ b.w.) on the relative expression of antioxidant defense genes vs. the reference phosphoglycerate kinase $(P g k 1)$ gene.

\begin{tabular}{cccccc}
\hline \multirow{2}{*}{ Gene } & \multicolumn{5}{c}{ Groups } \\
\cline { 2 - 6 } & AgNPs(BSA) & AgNPs(PEG) & AgNPs(Cit) & Ag $^{+}$ & Control \\
\hline Cat & $0.783 \pm 0.054^{\mathrm{a}}$ & $0.706 \pm 0.041$ & $0.818 \pm 0.057$ & $0.665 \pm 0.039^{\mathrm{a}}$ & $1.000 \pm 0.009^{\mathrm{b}}$ \\
Gsr & $0.819 \pm 0.036$ & $0.820 \pm 0.054$ & $0.890 \pm 0.038$ & $0.770 \pm 0.028^{\mathrm{a}}$ & $1.000 \pm 0.092^{\mathrm{b}}$ \\
Sod1 & $0.997 \pm 0.041$ & $1.004 \pm 0.031$ & $1.012 \pm 0.048$ & $0.953 \pm 0.011$ & $1.000 \pm 0.035$ \\
Sod2 & $0.793 \pm 0.046$ & $0.802 \pm 0.013$ & $0.894 \pm 0.016$ & $0.840 \pm 0.013$ & $1.000 \pm 0.112$ \\
Gpx1 & $0.595 \pm 0.054$ & $0.553 \pm 0.064$ & $0.800 \pm 0.174$ & $0.550 \pm 0.094$ & $1.000 \pm 0.362$ \\
Hmox1 & $0.895 \pm 0.154$ & $0.787 \pm 0.125$ & $0.823 \pm 0.062$ & $0.805 \pm 0.110$ & $1.000 \pm 0.162$ \\
\hline
\end{tabular}

Data are presented in arbitrary units as a ratio of the expression of the target gene to the expression of the reference gene $(P g k 1)$ with the control group calculated as 1 . All values are expressed as mean \pm SEM. ${ }^{\text {a, b }}$ Statistically significant difference from the silver-exposed group according to the Tukey post hoc test $(p<0.05)$. The same letters indicate statistically significant results. Cat—catalase; Gsr-glutathione reductase; Sod1—superoxide dismutase 1; Sod2—superoxide dismutase 2; Gpx1—glutathione peroxidase 1; Hmox1—heme oxygenase 1.

The expression of selected genes involved in hippocampus neurosteroidogenesis was downregulated by AgNPs based on the different coating materials used for stabilization. The changes in expression were the most pronounced in the groups treated with AgNPs coated with PEG and citrate. A significant reduction in the expression of both genes involved in neurosteroidogenesis and neurosteroid metabolism was observed. ANOVA showed a decrease in the expression of genes encoding the key enzymes involved in steroidogenesis, including steroidogenic acute regulatory protein (Star), hydroxysteroid (3ß) dehydrogenase 3 (Hsd3b3), hydroxysteroid $(17 \beta)$ dehydrogenase 1 (Hsd17b1), and hydroxysteroid $(17 \beta)$ dehydrogenase 10 (Hsd17b10) genes (ANOVA: $p=0.009, p=0.019$, $p=0.001$, and $p=0.012$, respectively) (Figure 3A, Table 2).

The post hoc analysis showed that the expression of Star and Hsd17b1 genes was lower in the AgNPs(PEG) group compared to the control group $(p<0.05$ and $p<0.001$, respectively). Similarly, the expression of Star and $\mathrm{Hsd} 3 \mathrm{b3}$ genes was reduced in the $\mathrm{Ag}^{+}$ group compared to the control group ( $p<0.01$ and $p<0.05$, respectively). The expression of $H s d 17 b 1$ gene was lower in the $\mathrm{AgNPs}(\mathrm{Cit})$ group than in the control group $(p<0.01)$. Furthermore, downregulation of $H s d 17 b 10$ expression was observed in AgNPs(BSA) and $\mathrm{Ag}^{+}$groups in comparison to the control group ( $p<0.05$ and $p<0.01$, respectively). No significant differences were noted in the expression of cytochrome P450, family 11, 
subfamily a, polypeptide 1 (Cyp11a1) and hydroxysteroid (17ß) dehydrogenase 3 (Hsd17b3) genes (Figure 3A, Table 2).

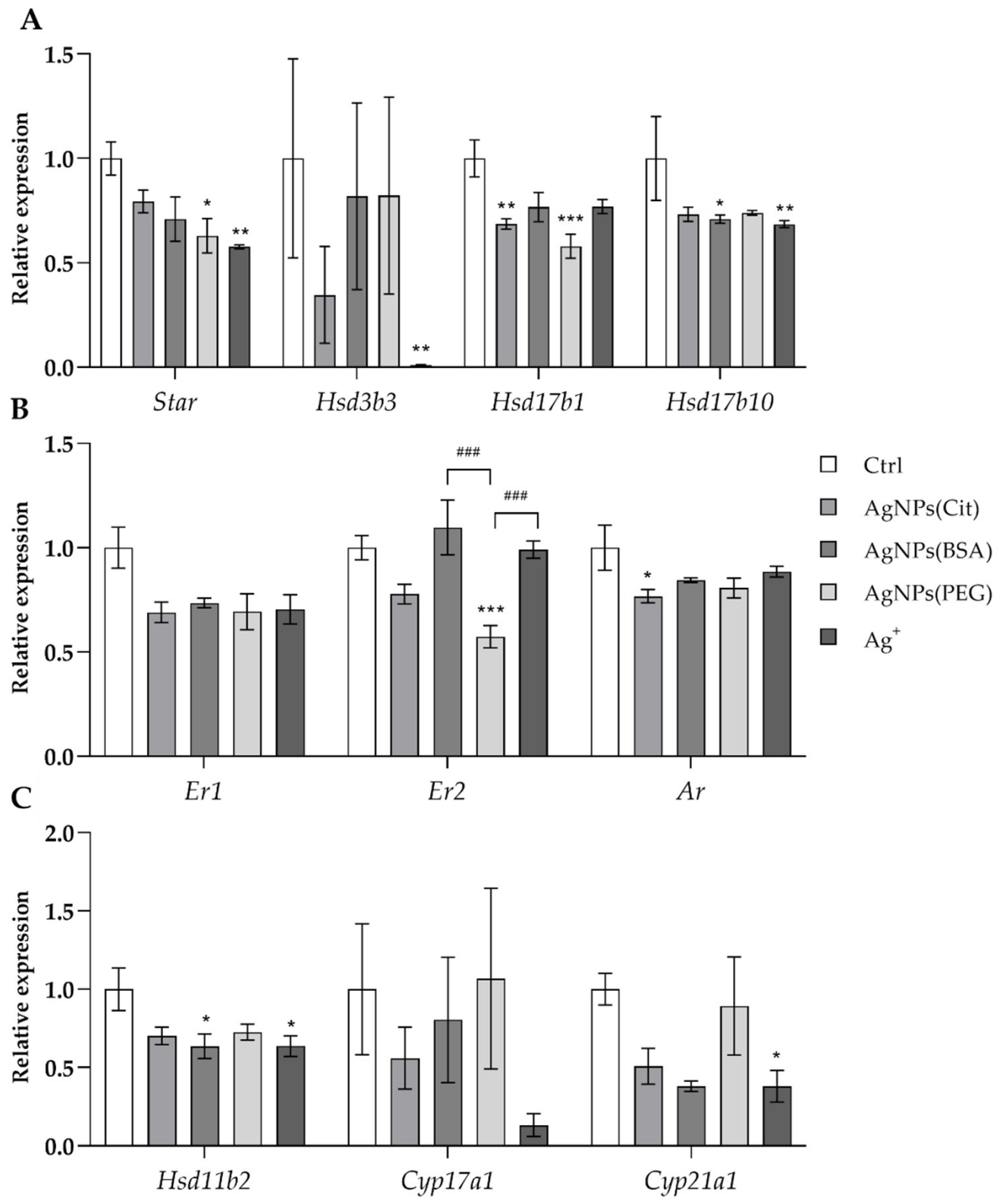

Figure 3. Relative expression of the genes involved in neurosteroid synthesis and metabolism vs. the reference phosphoglycerate kinase ( $P g k 1)$ gene in the hippocampus of rats exposed to AgNPs with different types of coating (citrate, bovine serum albumin (BSA), and polyethylene glycol (PEG)) or $\mathrm{Ag}^{+}$: $\mathrm{PEG}$ ) or $\mathrm{Ag}^{+}:(\mathrm{A})$ - steroidogenesis genes (Star (steroidogenic acute regulatory protein), Hsd3b3 (hydroxysteroid (3ß) dehydrogenase 3), Hsd17b1 (hydroxysteroid (17 $\beta$ ) dehydrogenase 1), Hsd17b10 (hydroxysteroid (17ß) dehydrogenase 10)); (B)—steroid metabolism genes (Er1 (estrogen receptor 1), $E r 2$ (estrogen receptor), $A r$ (androgen receptor)); (C)-glucocorticosteroid synthesis genes (Hsd11b2 (hydroxysteroid 11ß-dehydrogenase 2), Cyp17a1 (cytochrome P450, family 17, subfamily a, polypeptide 1), Cyp21a1 (cytochrome P450, family 21, subfamily a, polypeptide 1)). Data are presented in arbitrary units as a ratio of the expression of the target gene to the expression of the reference gene $(P g k 1)$ with the control group calculated as 1 . All values are presented as mean $\pm \mathrm{SEM}$. $*, * * * * *$ Significantly different from the control group $\left({ }^{*} p<0.05,{ }^{* *} p<0.01,{ }^{* * *} p<0.001\right)$ (Tukey post hoc test). ${ }^{\# \#}$ Significant differences between the groups exposed to AgNPs or $\mathrm{Ag}^{+}\left({ }^{\# \#} p<0.001\right)$ (Tukey post hoc test). 
Table 2. Effect of oral administration of AgNPs with different types of coating (citrate, bovine serum albumin (BSA), and polyethylene glycol (PEG)) or $\mathrm{Ag}^{+}(0.5 \mathrm{mg} / \mathrm{kg}$ b.w.) on the relative expression of the genes involved in neurosteroid synthesis and metabolism vs. the reference phosphoglycerate kinase $(P g k 1)$ gene.

\begin{tabular}{cccccc}
\hline \multirow{2}{*}{ Gene } & \multicolumn{5}{c}{ Groups } \\
\cline { 2 - 6 } & AgNPs (BSA) & AgNPs(PEG) & AgNPs(Cit) & Ag $^{+}$ & Control \\
\hline Cyp11a1 & $0.804 \pm 0.400$ & $1.067 \pm 0.577$ & $0.740 \pm 0.209$ & $0.726 \pm 0.130$ & $1.000 \pm 0.054$ \\
Hsd17b3 & $0.901 \pm 0.143$ & $0.883 \pm 0.112$ & $0.873 \pm 0.068$ & $0.671 \pm 0.080$ & $1.000 \pm 0.067$ \\
Srd5a1 & $1.242 \pm 0.067$ & $1.006 \pm 0.083$ & $1.139 \pm 0.059$ & $1.141 \pm 0.018$ & $1.000 \pm 0.065$ \\
Sult2a2 & $0.812 \pm 0.256$ & $0.871 \pm 0.459$ & $1.215 \pm 1.069$ & $0.689 \pm 0.332$ & $1.000 \pm 0.235$ \\
Cyp19a1 & $0.595 \pm 0.054$ & $0.553 \pm 0.064$ & $0.800 \pm 0.174$ & $0.550 \pm 0.094$ & $1.000 \pm 0.362$ \\
\hline
\end{tabular}

Data are presented in arbitrary units as a ratio of the expression of the target gene to the expression of the reference gene $(P g k 1)$ with the control group calculated as 1 . All values are presented as mean $\pm S E M$. Cyp11a1-cytochrome P450, family 11, subfamily a, polypeptide $1 ;$ Hsd17b3 — hydroxysteroid (17 $\beta$ ) dehydrogenase 3; Srd5a1—steroid$5 \alpha$-reductase, $\alpha$-polypeptide 1 (3-oxo-5 $\alpha$-steroid delta 4-dehydrogenase $\alpha$-1); Sult2a2-sulfotransferase family $2 \mathrm{~A}$, dehydroepiandrosterone (DHEA)-preferring, member 2; Cyp19a1—cytochrome P450, family 19, subfamily a, polypeptide 1 .

In the case of the expression of genes involved in steroid metabolism, ANOVA revealed that the transcription levels of androgen receptor $(A r)$ and both estrogen receptor 1 and 2 (Er1 and Er2) genes were reduced in the hippocampus of AgNPs-treated animals (ANOVA: $p=0.030, p=0.001$, and $p=0.039$, respectively). Ar gene expression was reduced in the $\operatorname{AgNPs}(\mathrm{Cit})$ group compared to the control group (post hoc: $p<0.05$ ), while Er2 gene expression was lower in the AgNPs(PEG) compared to the control group (post hoc: $p<0.001$ ) as well as AgNPs(BSA) and $\mathrm{Ag}^{+}$groups (post hoc: $p<0.001$ for both). No statistically significant differences were observed in the expression of Srd5a1, Sult2a2, and Cyp19a1 (Figure 3B, Table 2).

Additionally, ANOVA revealed statistically significant downregulation of glucocorticosteroidogenesis genes, including hydroxysteroid $11 \beta$-dehydrogenase 2 (Hsd11b2), cytochrome P450, family 21, subfamily a, polypeptide 1 (Cyp21a1), and cytochrome P450, family 17, subfamily a, polypeptide 1 (Cyp17a1) (ANOVA: $p=0.029, p=0.026$, and $p=0.046$, respectively). Post hoc analysis showed that the expression of Hsd11b2 and Cyp21a1 genes was lower in the $\mathrm{Ag}^{+}$group, and the expression of $\mathrm{Hsd11b2}$ was lower in the AgNPs(BSA) group than in the control rats ( $p<0.05$ for all comparisons) (Figure $3 C$, Table 2 ).

\subsection{Fisher's Linear Discriminant Analysis}

Fisher's LDA was carried out in order to summarize the results and obtain linear combinations (linear discriminants) of the studied parameters that allow the best distinction of the experimental groups. The results of Fisher's LDA of the experimental data are illustrated in Figure 4. The vectors shown in Figure 4B clarified the correlations between the values of the relevant parameters and two of the most data-separating combinations $\left(\mathrm{LDA}_{1}\right.$ and $\mathrm{LDA}_{2}$ ). Moreover, the vectors indicated the direction in which the related parameters specify the separation of the experimental groups presented in Figure 4A. The results of LDA help in understanding and organizing the variance analysis results in addition to confirming them.

The results of Fisher's LDA revealed that the parameters that correlated the most between the $\mathrm{LDA}_{1}$ and $\mathrm{LDA}_{2}$ combinations, differentiating the studied experimental groups, were the following: (1) the levels of DHEA, DHEAS, progesterone, $17 \alpha$-progesterone, testosterone, and DHT among the neurosteroids in the hippocampus; (2) the activity of SOD among the antioxidant defense enzymes; and (3) the expression of Hsd17b10 among the genes involved in neurosteroid synthesis and metabolism (Figure 4B). The control group stood out from the remaining groups, irrespective of the chemical form of silver administered and the coating material used (Figure 4A). The experimental groups were differentiated based on the value of the $\mathrm{LDA}_{2}$ coefficient, which correlated the most with the levels of progesterone, $17 \alpha$-progesterone, and testosterone, and the expression of $H s d 17 b 10$ 
gene (positively correlated with $\mathrm{LDA}_{1}$ ). The $\mathrm{Ag}^{+}$group was differentiated based on the value of the $\mathrm{LDA}_{1}$ coefficient, which correlated the most with the levels of DHEA, DHEAS, and DHT (positively correlated with $\mathrm{LDA}_{1}$ ), as well as the level of SOD (negatively correlated with $\mathrm{LDA}_{1}$ ). Importantly, this group was separated from the other groups that received nanoparticles with different types of coating, as reflected by its position relative to the horizontal axis showing the $\mathrm{LDA}_{1}$ coefficient (Figure $4 \mathrm{~A}$ ). The position of the $\mathrm{Ag}^{+}$ group on the graph is determined by the levels of neurosteroids and the parameters related to their synthesis and metabolism, including the levels of DHEA, DHEAS, and DHT, and the expression of $H s d 17 b 10$ gene.

A

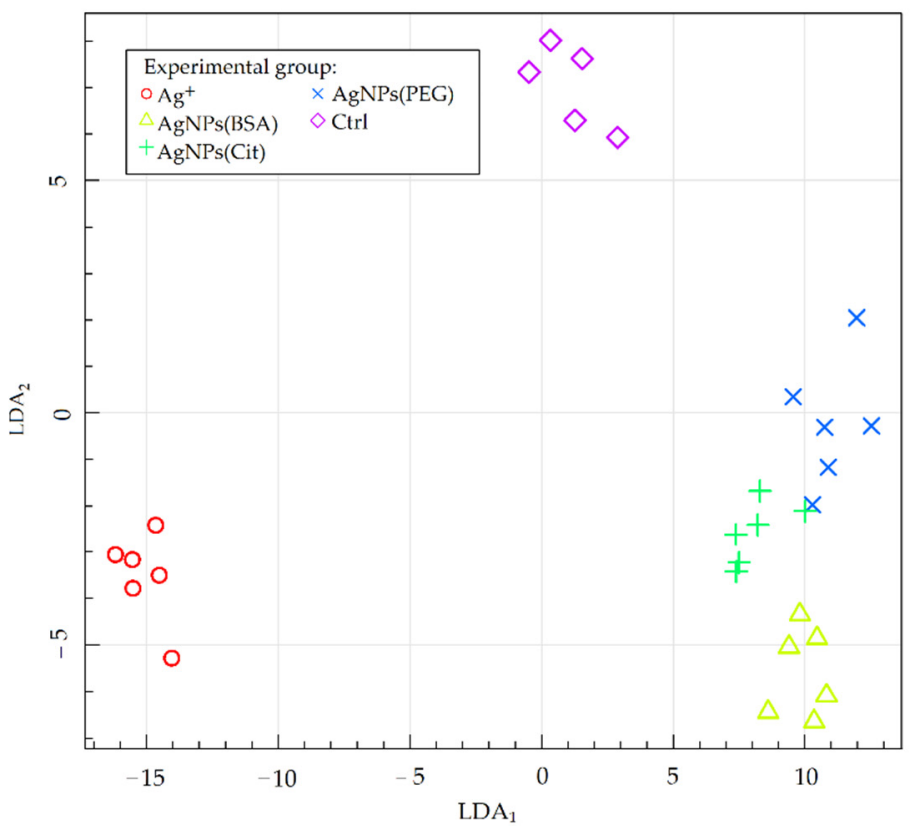

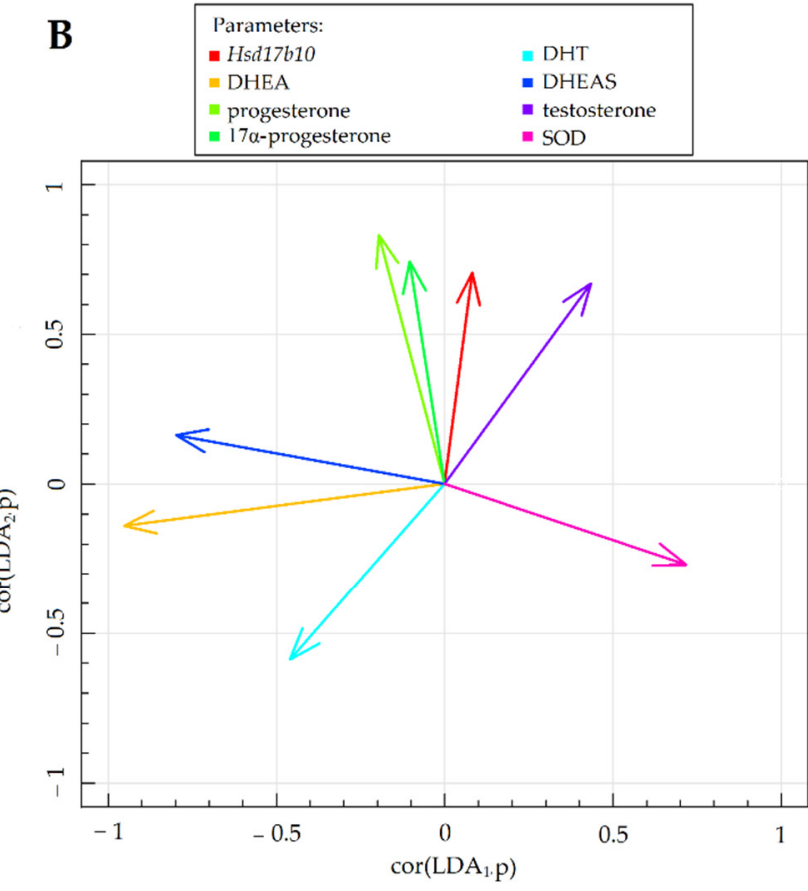

Figure 4. Fisher's LDA: (A) - experimental data on the plane spanned by two of the most dataseparating LDAs; (B)—parameters contributing the most to LDAs. Hsd17b10 — gene expression of hydroxysteroid (17 $\beta$-beta) dehydrogenase 10; DHEA-level of dehydroepiandrosterone; DHTlevel of dihydrotestosterone; DHEAS-level of dehydroepiandrosterone sulfate; SOD_activity of superoxide dismutase.

\section{Discussion}

Due to the widespread use of AgNPs in the food industry and medicine, as well as the increasing environmental risk associated with exposure to AgNPs, researchers have been investigating the safety of nanomaterials use [9]. AgNPs are found in a wide range of household products used on a daily basis, such as biomedicine products, textiles, hygiene and personal care items, food storage supplies, and so on [21]. Additionally, AgNPs have been studied as potential drug delivery and radiosensitizing efficacies in gliomas as well as agents for diagnosing and treating neurodegenerative diseases [22]. This extensive usage of AgNPs and their proven ability to cross biological barriers, such as the blood-brain barrier, have raised concerns about their potential influence on brain functions. Results obtained by Recordati et al. showed high deposition of silver in the brain after oral exposure of environmentally relevant dose of citrate-coated AgNPs at the end of the administration as well as after 4 weeks of recovery that highlighted slow elimination of Ag from the brain structures [23]. Our previous study has also shown that oral administration of AgNPs at a relatively small concentration resulted in a time-dependent accumulation of silver in the brain, particularly in the hippocampus, and simultaneous deterioration of learning skills in rats $[16,24]$. Additionally, our recent studies demonstrated that the effect of AgNPs on cognitive functions is determined by the coating used for the stabilization of these 
nanoparticles. It was found that exposure to AgNPs coated with BSA and PEG, as well as $\mathrm{AgNO}_{3}$ as a source of $\mathrm{Ag}^{+}$, was associated with impairment of hippocampal-dependent cognitive functions [24]. Taking into account the results of our studies and the possible toxicity of AgNPs toward the central nervous system (CNS), in the present study we investigated the mechanisms underlying the observed impairment of cognition functions after oral administration of AgNPs at environmentally relevant concentrations.

Experimental evidence shows that the physicochemical properties of nanoparticles are one of the key factors determining their fate in the body [1,6]. Studies have indicated that besides particle size, synthesis methods, elemental composition, surface charge and area, aggregation, and dissolution in body fluids, surface coating also affects the tissue biodistribution and cellular uptake of nanoparticles as well as their reactivity and toxicity $[6,25,26]$. Of the mentioned factors, surface modification has the most significant influence on the immune system and is likely to determine the toxicity of nanoparticles [27,28]. For this reason, in the present study we attempted to elucidate the mechanisms responsible for the observed toxicity of AgNPs determined by the coating agent (BSA, PEG, citrate) used for their surface stabilization.

AgNPs used in the food packages limit the development of spoilage microorganisms by releasing $\mathrm{Ag}^{+}$ions to generate ROS, which can destroy bacterial membrane and thus control the growth of microorganisms [29]. Although these functional properties of nanoparticles are advantageous for the food industry, they are undesirable as the nanoparticles come in contact with cells in the human body. Oxidative stress is proposed as the main mechanism behind nanoparticle-induced toxicity due to the release of Ag+ after infiltrating the cells and AgNPs intracellular degradation [26,30]. The brain is particularly susceptible to ROS because of its high oxygen consumption, weak antioxidative capability, and high content of peroxidation-prone unsaturated fatty acids [31]. Oxidative stress has been proven as an important pathogenesis factor in neurodegenerative diseases, such as Alzheimer's and Parkinson's disease. ROS may also induce neuronal cell death and brain inflammation. In addition, ROS modulate the functions of neuronal ion channels, contributing to long-term memory dysfunction [32].

Nanosilver has been known to induce oxidative stress in the CNS [33-36]. AgNPs increase the production of free radicals, provoke lipid and protein peroxidation, and disrupt mitochondrial functions [28]. Our previous studies have shown a time-dependent silver deposition in the brain and the induction of oxidative stress in the brain of animals injected with BSA-coated AgNPs [8,37] and in rats that inhaled diesel exhaust containing nanoparticles which included silver [38]. Though in the present study we did not directly assess the level of oxidative stress, some indirect evidence suggests that oxidative stress in the AgNPs-treated group was higher compared to the control group. The SOD activity was found to be significantly elevated in $\mathrm{AgNPs}(\mathrm{PEG})$ ond $\mathrm{AgNPs}(\mathrm{BSA})$ group compared to $\mathrm{AgNPs}(\mathrm{Cit}), \mathrm{Ag}^{+}$, and control groups. These results are in agreement with those of our previous study [8]. These findings are also in line with the study of Skalska et al. [34], in which no changes in SOD activity were observed in the brain of rats exposed to AgNPs(Cit), although the authors reported an increase in GPx activity. Our study confirmed this observation, as we found increased GPx activity in the groups exposed to AgNPs(Cit) or AgNPs(BSA). Similar findings were also reported by Dănilă et al. [39], who studied the effects of $\mathrm{AgNPs}(\mathrm{Cit})$ and AgNPs functionalized with polyphenols on the offspring of female rats treated with nanoparticles. The authors found that the SOD activity in the hippocampus and cerebellum did not change significantly in the Cit-AgNPs group, although it was lowered by exposure to AgNPs coated with plant extracts [39]. On the contrary, Yousef et al. [40] observed decreased SOD activity in the brain of rats treated with either AgNPs or AgNPs combined with $\mathrm{Fe}_{2} \mathrm{O}_{3}$ nanoparticles. In both groups of animals a significant decline of antioxidant enzymes activity (not only SOD but also CAT and GPx) was observed [40].

To elaborate the mechanisms behind the changes observed in the activity of antioxidant enzymes, we analyzed the impact of differently coated AgNPs on the expression of genes 
related to the antioxidant defense system (Sod1, Sod2, Cat, Gpx1, Gsr, Hmox1) as well as the level of TBARS and TAS in the hippocampus of the studied groups of rats. However, our results showed only downregulation of Cat in the AgNPs(BSA)-exposed group. This result is similar to that reported by Chen et al. [41], who observed no differences in the expression of Sod1, Hmox1, and Gpx in the brain tissue of mice treated intravenously with nanosilver. Dabrowska-Bouta et al. [42] also observed no significant influence of AgNPs on the expression of Sod1 gene in the rat brain cortex, although Sod2 expression was elevated by nearly 30\%. Conversely, Dayem et al. [35] found that the expression of SOD2 and CAT was decreased in human neuroblastoma SH-SY5Y cells treated with AgNPs, while the expression of GPX1 remained unchanged. Additionally, Davenport et al. [43] showed an impact of nanosilver on the expression of Hmox 1 in the hippocampi of intranasally exposed mice.

We found that AgNPs affected the overall antioxidant status of the hippocampus of exposed animals. While TAS was similar in the groups receiving PEG- or citrate-coated $\mathrm{AgNPs}_{\mathrm{f}} \mathrm{Ag}^{+}$as compared to the control group, it was found to be decreased significantly in the hippocampus of AgNPs(BSA)-treated animals. Analogous outcomes were reported by Yousef et al. [40], who found that the total antioxidant capacity of the brain was lowered by $22.4 \%$ in the group treated with AgNPs and by $35.8 \%$ in the group treated with AgNPs and $\mathrm{Fe}_{2} \mathrm{O}_{3}$. Similar results were also shown by Attia et al. [44], who also found reduced TAS levels in mice exposed to high doses of citrate-coated AgNPs. In addition, recently, Opris et al. [45] also found increased lipid peroxidation products and simultaneous severe ultrastructural changes in neurons and astrocytes in the hippocampus in rats orally exposed to AgNPs phytosynthesized with Cornus mas L. extract. This is in line with the results of our study, which also found elevated TBARS levels, but only in animals that received BSAcoated AgNPs. Taken together, the results suggest that AgNPs can affect the antioxidant defense system in the hippocampus. However, the exact effects of nanoparticles seem to vary depending on the specific form of silver used and the functionalization applied.

AgNPs-induced oxidative stress in the brain has been reported to promote astrocyte proliferation, probably as a response to protect nearby neurons. It is a kind of defense mechanism as astrocytes and other glial cells are the principal cells involved in brain response to injury and in the protection of the neurons against oxidative stress and metal toxicity [46]. Recordati et al. [23] showed dose-dependent glial cells activation after treatment with citrate-coated AgNPs, but not ionic Ag in mice orally exposed to AgNPs or silver acetate as a source of Ag ions. Additionally, they found swelling of astrocytic perivascular end-feet in both Ag-exposed mice. However, at higher concentrations AgNPs change astrocyte morphology and provoke caspase-dependent cytotoxicity, which eventually leads to cell death $[36,46]$. Simultaneously, neurons themselves can also be affected, as evidenced by inhibited neurite growth and reduction in the number of synapses [46]. Since astrocytes serve an important role in the supply of cholesterol, the primary substrate for neurosteroid synthesis in which both them and primary neurons are involved, these observations suggest that nanoparticulate silver could exert a detrimental effect on steroidogenesis in the brain $[47,48]$. Furthermore, in the intracellular space AgNPs-mediated ROS production has been shown to disrupt mitochondrial functions $[6,13,18]$. Steroidogenesis is one of the key functions of mitochondria [49]. Therefore, an important part of the present study was the analysis of whether AgNPs induced changes in the metabolism of neuroactive steroids, based on the assessment of steroid content and expression of genes involved in neurosteroid metabolism in the hippocampus. Neurosteroids are steroid hormones synthesized in the brain or peripheral neurons. They are either formed de novo from cholesterol or originate from peripheral tissues, such as endocrine glands including gonads and adrenal glands. The term "neuroactive steroids" refers to the steroids that act on the CNS [50]. Increased oxidative stress may also result from impaired steroid synthesis [51]. ROS inhibits steroidogenesis mainly by reducing the availability of the substrate for steroid synthesis by decreasing the expression of StAR protein in cells, as well as the activity of steroid biosynthetic pathway enzymes, including $3 \beta$-hydroxysteroid dehydrogenase and cytochrome P450scc associated with cholesterol desmolase [52]. On the other hand, AgNPs 
induce dysfunction of the mitochondria. The major mitochondrial ultrastructural changes noticed in animals treated with AgNPs suggested mitochondrial dysfunction as a response to stress conditions, consisting of swelling, altered cristae, and elongation $[34,44,45]$. Reported changes in mitochondrial functions are probably resulting from the interactions of $\mathrm{Ag}^{+}$ions with the thiol groups present in the inner mitochondrial membrane [53-55]. In the present study, we observed that the genes involved in steroidogenesis, such as Star, $H s d 3 b 3$, and Hsd17b1, were significantly downregulated, which confirms the above hypothesis. Inhibition of the expression of genes associated with steroid biosynthesis or their activity was also demonstrated in our previous study on the testis of rats intravenously exposed to BSA-coated AgNPs [12]. Additionally, Lyu et al. [56] identified steroid hormone synthesis as one of the molecular pathways disturbed as a result of oral exposure to AgNPs. Furthermore, downregulation of the expression of Star gene, which encodes StAR protein that regulates the rate-limiting step in steroid biosynthesis, suggests that AgNPs impaired de novo hippocampal steroidogenesis.

Neurosteroids exert significant biological effects on the brain because they act as allosteric modulators of various neurotransmitters receptors, including gamma-aminobutyric acid A, N-methyl-D-aspartate, and serotonin receptors, and therefore regulate various brain functions such as cognition, locomotion, stress reactions, and anxiety [51]. In terms of cognitive skills, neurosteroids act as modulators of the activity and plasticity of neurons, synaptic conduction processes, neurogenesis, and learning as well as memory consolidation processes [57]. Oral exposure to $\mathrm{AgNPs}$ and $\mathrm{Ag}^{+}$caused significant changes in the concentration of steroids in the hippocampus of rats, including, in particular, an increase in pregnenolone level in the $\mathrm{AgNPs}(\mathrm{PEG})$ group and a reduction in pregnenolone in the $\mathrm{Ag}^{+}$ group, as well as a reduction in progesterone and 17 $\alpha$-progesterone in the AgNPs (BSA), AgNPs (Cit), and $\mathrm{Ag}^{+}$groups, an increase in 4-androsten-11 $\beta$-ol-3.17-dione in AgNPs (BSA) and $\mathrm{Ag}^{+}$groups, and an increase in DHT in $\mathrm{AgNPs}$ (BSA), $\mathrm{AgNPs}(\mathrm{Cit})$, and $\mathrm{Ag}^{+}$groups The behavioral test used to assess learning skills in these rats revealed impaired formation and consolidation of memory traces in the $\operatorname{AgNPs}(\mathrm{BSA})$-treated group. The effects of this impairment were shown to be deficits of memory acquisition and maintenance of long-term memory [24]. Other authors also observed steroid-related behavioral disorders, including anxiety-like behavior in mice exposed to citrate-coated AgNPs [45].

The present study suggested that $\mathrm{Ag}^{+}$and $\mathrm{AgNPs}$ differed in their mode of action on cells, as confirmed by the results of Fisher's LDA. The $\mathrm{Ag}^{+}$group was separated from both the control group and the groups that received AgNPs with different types of coating materials. This group was characterized by altered steroid synthesis and metabolism, which subsequently resulted in reduced levels of initial steroidogenesis metabolites, including progesterone and $17 \alpha$-progesterone, and increased levels of highly potent steroid hormones that negatively affect the CNS (DHEA and DHEAS). Although decreased DHEA levels have been linked to several age-related diseases, in vitro and in vivo studies showed that this steroid can also exhibit neurotoxic effects at high concentrations [58,59]. Interestingly, a significant increase in the levels of DHEA and DHEAS was found only in the $\mathrm{Ag}^{+}$group. These outcomes may result from AgNPs' potential to induce mitochondrial damage, which other authors noted and described [53-55].

Interestingly, the outcomes of the present study revealed that surface functionalization is one of the most important factors influencing the biological effects of nanoparticles. The most significant changes observed in the present study include levels of oxidative stress and in the production of neurosteroids, with differences observed both in the concentration of neurosteroids and the expression of genes involved in their metabolism. These alterations were predominantly caused by BSA-coated AgNPs. The results of ANOVA and LDA showed that AgNPs(BSA) increased the activity of SOD and GPx and decreased the levels of the initial steroidogenesis metabolites (progesterone). The effect of AgNPs(BSA) was also indicated by decreased levels of androgen steroids, such as testosterone, and a simultaneous increase in the DHT concentration in the hippocampus, which suggests a probable reduction of testosterone levels by $5 \alpha$-reductase in the peripheral tissues. On the 
other hand, no changes in the expression of $\operatorname{Srd5a1}$ gene, which encodes $5 \alpha$-reductase, were observed in the hippocampus. In addition, only AgNPs(BSA) reduced the expression of the Hsd17b10 gene that encodes $17 \beta$-hydroxysteroid dehydrogenase 10 (17 $\beta$-HSD10) enzyme. Interestingly, $17 \beta-H S D 10$ is a multifunctional mitochondrial enzyme that plays a key role in the metabolism and aging process of the CNS [60]. In the brain, this enzyme is involved in the conversion of androgen to estrogen, which further contributes to the pathology of neurodegenerative diseases by influencing memory mechanisms and mood control [61]. Importantly, reduced expression of $\mathrm{Hsd} 17 \mathrm{~b} 10$ gene was noted in $\mathrm{AgNPs}(\mathrm{BSA})$ and $\mathrm{Ag}^{+}$ groups. Behavioral tests revealed that the animals of these two groups (AgNPs(BSA) and $\mathrm{Ag}^{+}$groups) showed long-term memory and memory consolidation disorders, which are the characteristic symptoms of neurodegenerative diseases, such as Alzheimer's disease. The $17 \beta$-HSD10 enzyme also contributes to the maintenance of mitochondrial integrity and is involved in the oxidation of fatty acids and steroids [62]. A reduction in the level of this enzyme was associated with enhanced oxidative stress, which is the characteristic effect of $\mathrm{Ag}^{+}$ions and is responsible for mitochondrial dysfunction. Based on the experimental results, the toxic effects of $\mathrm{AgNPs}(\mathrm{BSA})$ can be attributed to the mechanism of $\mathrm{Ag}^{+}$ions release, which is consistent with the results of previous studies. Besides the accumulation of a significant amount of Ag (determined by nanoSIMS) in the hippocampus of animals exposed to low doses of AgNPs, the presence of $\mathrm{Ag}^{+}$ions (rather than nanoparticles) was also noted in our previous study [16].

The variation observed in the effects of AgNPs coated with different types of coating in the hippocampus can be related to the different degrees of stability provided by the different coating materials in the biological fluids, especially in the gastrointestinal tract $[5,63]$. BSA cannot form a permanent coating on AgNPs, as it is prone to digestion by the proteolytic enzymes in the gastrointestinal tract. After the digestion of BSA coating, AgNPs are surrounded by a protein corona formed by other available compounds, mainly food proteins [64]. The amount of $\mathrm{Ag}^{+}$ions released into the surrounding environment is determined by the coating material used on AgNPs.

The present study revealed only slight differences in the effects of AgNPs coated with PEG and citrate. AgNPs(Cit) induced higher levels of oxidative stress, as demonstrated by elevated levels of GPx and TBARS which may indicate that the oxidative stress-alleviating effect of antioxidant enzymes is increased, which further enhances lipid peroxidation. This condition can have serious implications for brain tissues, due to high amounts of unsaturated fatty acids which are highly susceptible to damage by ROS and the substantial toxicity of lipid peroxidation products on neurons.

Nevertheless, our previous results indicate that AgNPs(PEG) elicit a more robust systemic response by inducing systemic inflammation. In conclusion, the results of the present study confirmed the neurotoxic effects of AgNPs and showed that these effects could be minimized by modifying the physicochemical properties of nanoparticles, and the use of appropriate and coating is the most effective approach for this purpose.

\section{Materials and Methods}

\subsection{Preparation and Characterization of Silver Nanoparticles}

In the in vivo experiment, the studied animals were exposed to AgNPs with three different types of surface coating. AgNPs with bovine serum albumin (BSA; PlasmaChem, Berlin, Germany) coating and a nominal diameter of $20 \pm 5 \mathrm{~nm}$ were prepared as described previously [65,66]. Briefly, $2 \mathrm{mg}$ of AgNPs was dispersed in $800 \mu \mathrm{L}$ of purified distilled water to form the nanoparticle stock solution. The stock solution was sonicated for $10 \mathrm{~min}$ on ice using a probe sonicator (Branson, Danbury, CT, USA) with $420 \mathrm{~J} \mathrm{~m}^{-3}$ total ultrasound energy. After sonication, $100 \mu \mathrm{L}$ of $15 \%$ BSA and $100 \mu \mathrm{L}$ of $10 \times$ phosphate-buffered saline (PBS) were added directly to the solution. AgNPs (nominal diameter of $25 \mathrm{~nm}$ ) coated with sodium citrate were obtained from NanoCom-posix (San Diego, CA, USA). These

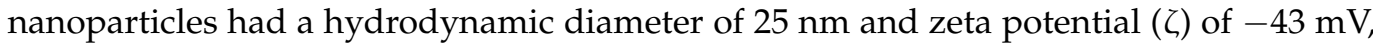
according to the manufacturer's information. 
PEGylated AgNPs were prepared by mixing poly(ethylene glycol) methyl ether thiol (PEG, 5000 Da; Sigma-Aldrich, St. Louis, MO, USA) and $1 \mathrm{mg}$ of AgNPs in $100 \mu \mathrm{L}$ of aqueous SH-PEG solution (1 mg of PEG dissolved in $100 \mu \mathrm{L}$ of water). Then, the reaction mixture was stirred for $2 \mathrm{~h}$ at room temperature. The zeta potential and hydrodynamic diameter of nanoparticles were determined by dynamic light scattering using the Zetasizer Nano ZS system (Malvern, UK) at $25^{\circ} \mathrm{C}$ with a scattering angle of $173^{\circ}$. Stock solutions of PEG-coated AgNPs (pH 7.4) were diluted in water, and their zeta potentials were measured in triplicate with 14-sub runs, by applying the Smoluchowski limit for the Henry equation with a setting calculated for practical use $(\mathrm{f}(\mathrm{ka})=1.5)$. In addition to zeta potential and hydrodynamic size, AgNPs with different types of coating (BSA, citrate, PEG) were evaluated for aggregation state and characterized by scanning electron microscopy (DSM 942, Carl Zeiss, Göttingen, Germany) as well as transmission electron microscopy (JOEL 1200 EX II, JOEL, Tokyo, Japan), and the results have been already published [3]. The characteristics of the AgNPs used in the in vivo experiment are described in Table 3.

Table 3. Characterization of AgNPs in water after dispersion (mean $\pm \mathrm{SD}$ ) (modified from MeczyńskaWielgosz et al. [65].

\begin{tabular}{cccc}
\hline & $\begin{array}{c}\text { BSA-Coated } \\
\text { AgNPs }\end{array}$ & $\begin{array}{c}\text { PEG-Coated } \\
\text { AgNPs }\end{array}$ & $\begin{array}{c}\text { Citrate-Coated } \\
\text { AgNPs }\end{array}$ \\
\hline Nominal size of Ag particles [nm] & $20 \pm 5$ & $25 \pm 5$ & $25 \pm 5$ \\
Dynamic light scattering [nm] & $84.4 \pm 3.7$ & $58.3 \pm 6.5$ & $27.5 \pm 5.6$ \\
Polydispersity index & 0.295 & $0.144 \pm 0.06$ & $0.308 \pm 0.05$ \\
Zeta potential [mV] & -33.6 & -30.2 & -32.5 \\
\hline
\end{tabular}

Data are expressed as mean \pm SD $(n=3)$.

\subsection{Animals and Experimental Design}

The in vivo experiment was conducted on 10-week-old male Wistar rats (Wistar Cmbd:Wi strain) $(\mathrm{n}=39)$, purchased from the Medical University of Bialystok, Center for Experimental Medicine (Polish Breeder's register no. 003, GLP Certificate 17/2018/DPL). The animals were placed under standard housing conditions (12 h light $/ 12 \mathrm{~h}$ dark cycles, temperature $22{ }^{\circ} \mathrm{C}$, relative humidity $55 \%$ ) and provided with both water and food ad libitum (Labofeed B maintenance diet, providing 67\% of energy from carbohydrates, $8 \%$ from fat, and $25 \%$ from protein). After a 1-week adaptation period, the rats were assigned to one of the following groups: $\operatorname{AgNPs}(\mathrm{BSA})$ group $(\mathrm{n}=8), \operatorname{AgNPs}(\mathrm{PEG})$ group $(\mathrm{n}=8)$, $\operatorname{AgNPs}($ Cit $)$ group $(n=8), \mathrm{Ag}^{+}$group $(n=8)$, or control $(n=7)$. The experimental animals received orally by gavage $0.5 \mathrm{mg} / \mathrm{kg}$ body weight (b.w.) of AgNPs or silver nitrate for 28 days, while the control group received $0.2 \mathrm{~mL}$ of $\mathrm{H}_{2} \mathrm{O}$ for 5 days a week. Changes in the weight of animals were monitored once a week throughout the experimental period. All the experimental procedures performed in the study were approved by the First Warsaw Local Ethics Committee for Animal Experimentation (application no. 788/2015, 25 May 2015) and carried out in accordance with the corresponding Polish legal regulations. The design of the experiment and description of the groups are provided in Figure 5.

\subsection{Tissue Collection and Preparation}

At the end of the experiment, the animals were sacrificed by isoflurane inhalation (Baxter Healthcare, Warsaw, Poland). The brains of the animals were excavated and rinsed in saline solution, and then the hippocampi were isolated from both hemispheres. The ventral parts were used for the analyses of total antioxidant status (TAS) and activities of glutathione peroxidase (GPx), glutathione reductase (GSR), and superoxide dismutase (SOD), as well as the level of lipid peroxidation (TBARS) and neurosteroids, while the dorsal parts were used for RNA isolation and gene expression analysis. Hippocampi were frozen in liquid nitrogen and stored at $-80^{\circ} \mathrm{C}$ for further biochemical analyses. To determine the antioxidant potential, the ventral parts were homogenized in PBS (pH 7.4; Sigma-Aldrich, St. Louis, MO, USA) in a tissue-to-buffer volume ratio of 1:5, using a homogenizer (Bio-Gen 
PRO 200, PRO Scientific, Oxford, MS, USA). The resulting homogenates were centrifuged for $5 \mathrm{~min}$ at $4{ }^{\circ} \mathrm{C}$ and $5000 \times g$ (Multifuge 3L-R centrifuge, Kendro, Hanau, Germany). After centrifugation, the supernatants were transferred to $200-\mu \mathrm{L}$ test tubes and frozen at $-80{ }^{\circ} \mathrm{C}$ for further analyses.

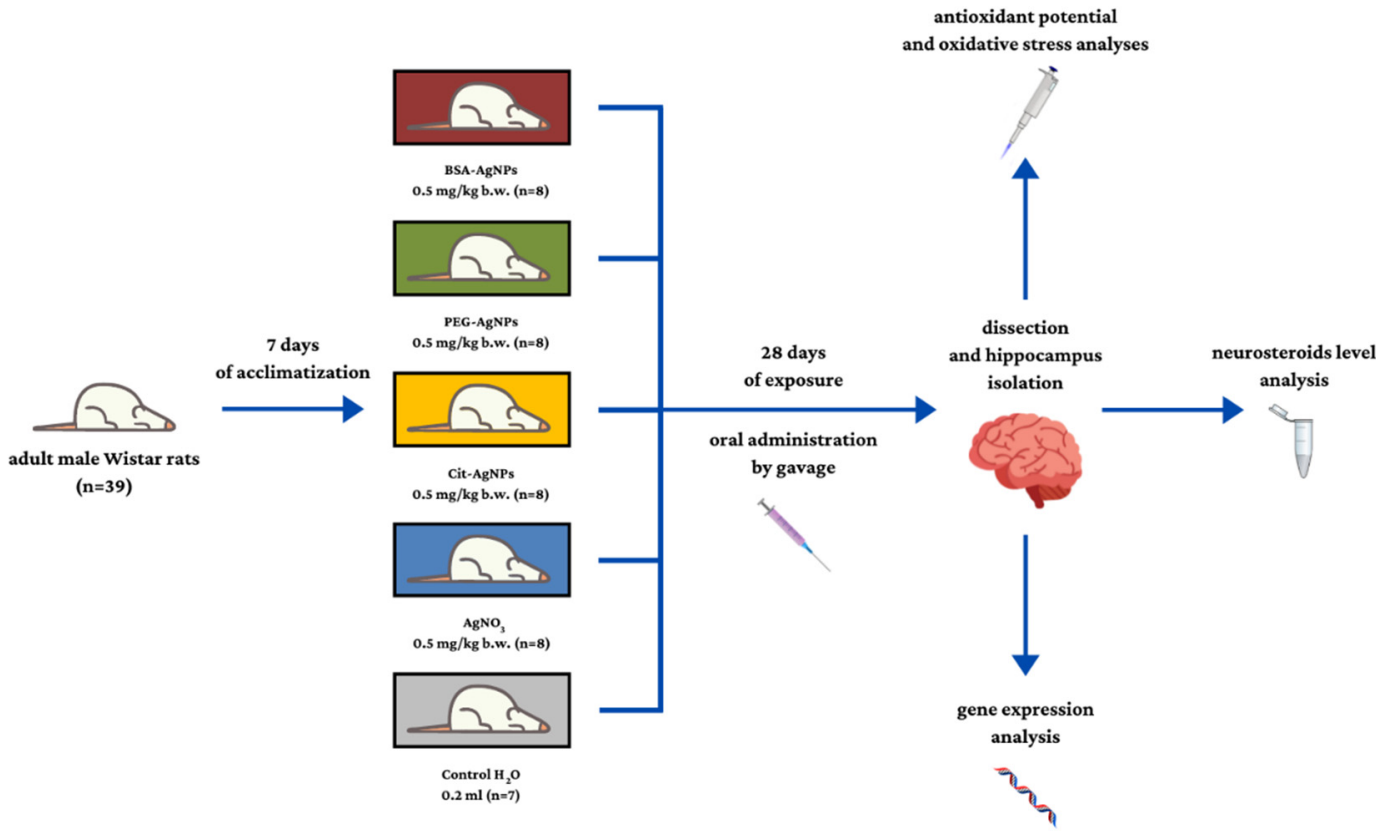

Figure 5. Scheme of the experimental design. Designed using elements by CCanva via http:/ Canva. com (accessed on 23 December 2021, version used Canva 2.0).

\subsection{Neurosteroid Level in the Hippocampus}

To determine the levels of neurotransmitters in the hippocampus (pregnenolone, progesterone, $17 \alpha$-progesterone, allopregnanolone, dehydroepiandrosterone (DHEA), dehydroepiandrosterone sulfate (DHEAS), androstenedione, $17 \beta$-estradiol, testosterone, and dihydrotestosterone (DHT)), a quantitative analysis was carried out using quadrupole time-of-flight tandem mass spectrometry (SCIEX TripleTOF 5600+ DuoSpray Source for SCIEX TripleTOF 5600+ (TurboIonSpray and APCI) (Framingham, MA, USA). Identification of neurotransmitters was performed using the commercially available steroid standards (Sigma-Aldrich, St. Louis, MO, USA). Methanol and acetonitrile were HPLC/MS grade (JT Baker, Deventer, The Netherlands).To prepare the sample for the analysis, rat hippocampi were homogenized with $800 \mu \mathrm{L}$ of acetonitrile and methanol mixture (1:1), and then vortexed (2000 rotations for $15 \mathrm{~min}$ ) and centrifuged (13,000 $\times \mathrm{g} \mathrm{rpm}$ for $15 \mathrm{~min})$. After centrifugation, the supernatants were transferred to glass autosampler vials and placed in an autosampler at $4{ }^{\circ} \mathrm{C}$. Chromatographic separation was performed using Hypersil chromatographic column (Phenomenex, Torrance, CA, USA), BDS C18, $150 \times 4.6 \mathrm{~mm}$, $5 \mathrm{~mm}$ with a Hypersil C18 guard column $(10 \times 2.1 \mathrm{~mm}$, size $5 \mu \mathrm{m})$. The mobile phase used for the analysis consisted of methanol:formic acid (99:1, $v / v)$ (A) and water:formic acid $(99: 1, v / v)(B)$, with the flow rate set constant at $500 \mu \mathrm{L} \mathrm{min}{ }^{-1}$. The gradient elution program was as follows: starting with 100\% A, 1.1-40 min linear gradient to $100 \%$ B, 40.1-55 min $100 \% \mathrm{~B}$, and $55.1-60 \mathrm{~min}$ linear gradient to $100 \% \mathrm{~A}$. The runtime was $60 \mathrm{~min}$. The mass spectrometry parameters for optimized detection were as follows: curtain gas $\left(\mathrm{N}_{2}\right)$ 25 psi, nebulizer gas $\left(\mathrm{N}_{2}\right) 20$ psi, heater gas $\left(\mathrm{N}_{2}\right) 50$ psi, ion source voltage floating $5500 \mathrm{~V}$, and source temperature $500{ }^{\circ} \mathrm{C}$. Samples with a heated electrospray ionization probe were measured in positive ionization mode. Every third sample analyzed using the Calibrant Delivery System (SCIEX) mass spectrometry system was autocalibrated using original calibrators (SCIEX). Method validation and quantitative analysis were carried out in the original SCIEX software (Analyst v1.7.1, PeakView v2.2, MasterView v1.3.1). 


\subsection{Antioxidant Potential and Oxidative Stress Analysis}

The antioxidant potential of hippocampus homogenates was analyzed by measuring the activity of GPx, GSR, and SOD as well as TAS. The activity of enzymes was assessed spectrophotometrically using dedicated kits (Ransel, GR, and Ransod kits for GPx, GR, and SOD, respectively; Randox Laboratories, London, UK), following the manufacturer's instructions, and light intensity was measured using Biochrom Anthos Zenyth 200 spectrophotometer (Cambridge, UK) at a wavelength of $505 \mathrm{~nm}$. The results of the enzyme activity analysis were expressed in U/g of tissue. TAS was also assessed spectrophotometrically using a dedicated Total Antioxidant Status kit (Randox Laboratories, London, UK), as per the manufacturer's instructions, and light intensity was measured using Biochrom Anthos Zenyth 200 spectrophotometer (Cambridge, UK) at a wavelength of $600 \mathrm{~nm}$. The results of the TAS analysis were expressed in $\mu \mathrm{mol} / \mathrm{g}$ of tissue.

The level of lipid peroxidation was assessed as the concentration of TBARS and other secondary products of lipid peroxidation such as malondialdehyde (MDA) [67]. The hippocampus supernatants were mixed with $0.1 \mathrm{M}$ sulfuric acid and $1 \%$ thiobarbituric acid (TBA) (Sigma-Aldrich, St. Louis, MO, USA). After warming at $90^{\circ} \mathrm{C}$ for $1 \mathrm{~h}$, the samples were cooled and mixed with n-butanol, and then the tubes containing samples were placed in ice until the two phases separated. The upper phase was isolated and incubated with TBA. Subsequently, the isolates were centrifuged for $5 \mathrm{~min}$ at $2000 \times g$, and the absorbance was measured at $534 \mathrm{~nm}$ using Biochrom Anthos Zenyth 200 spectrophotometer (Cambridge, UK). TBARS concentration was calculated from a standard curve based on 1,1,3,3-tetramethoxypropane which converts to MDA upon hydrolysis during the assay, and the results were expressed as nmol MDA/mg tissue.

\subsection{Gene Expression Analysis in Rat Hippocampus}

Gene expression analysis was performed using the quantitative polymerase chain reaction (qPCR) method. RNA extraction from the rat hippocampus samples was carried out using RNeasy Lipid Tissue Mini Kit (Qiagen, Hilden, Germany), following the manufacturer's instructions. The concentration and purity of RNA were determined using NanoDrop ${ }^{\mathrm{TM}} 2000$ spectrophotometer (Thermo Fisher Scientific, Waltham, MA, USA). Based on the absorbance ratios (A260/A280 and A260/A230), the samples were confirmed as pure and lacking protein residues. RNA integrity of several randomly selected samples was assessed using Agilent Bioanalyzer 2100 with an RNA 6000 Nano LabChip ${ }^{\circledR}$ kit (Agilent Technologies, Palo Alto, CA, USA). The analysis showed a minimal degradation rate for RNA, with an RNA integrity number (RIN) of greater than 9. For PCR analysis, $1 \mu \mathrm{g}$ of RNA was converted to its cDNA in a $20-\mu \mathrm{L}$ reaction volume, using RT2 First Strand Kit (Qiagen, Hilden, Germany). Then, cDNA was diluted with $91 \mu \mathrm{L}$ of ultraPure DNase/RNase-free distilled water and used for gene expression analysis which was carried out using RT2 Profiler PCR Arrays (Qiagen, Hilden, Germany), in accordance with the manufacturer's instructions. RT2 Profiler PCR Arrays included primers for specific genes (Ar, cat. no. PPR44497A; Cat, cat. no. PPR42937A; Cyp11a1, cat. no. PPR42479A; Cyp17a1, cat. no. PPR44710A; Cyp19a1, cat. no. PPR47164A; Cyp21a1, cat. no. PPR66742A; Esr1, cat. no. PPR44939B; Esr2, cat. no. PPR48980A; Gpx1, cat. no. PPR45366A; Gsr, cat. no. PPR46891B; Hsd3b, cat. no. PPR48776C; Hsd11b2, cat. no. PPR44719A; Hmox1, cat. no. PPR57718A; Hsd17b1, cat. no. PPR44938B; Hsd17b3, cat. no. PPR45110A; Hsd17b10, cat. no PPR42824A; Sod1, cat. no. PPR43506A; Sod2, cat. no. PPR57578A; Srd5a1, cat. no. PPR43427F; Star, cat. no PPR45414A; Sult2a2, cat. no PPR75581A) (Qiagen, Hilden, Germany). The $25-\mu \mathrm{L}$ reaction mixture used for PCR consisted of $1 \mu \mathrm{L}$ of cDNA template, $11.5 \mu \mathrm{L}$ of DNase/RNase-free distilled water, and $12.5 \mu \mathrm{L}$ of RT2 SYBR Green/ROX qPCR Master Mix along with Hot-Start DNA Taq Polymerase, SYBR green, and ROX reference dye (Qiagen, Hilden, Germany). Amplification was performed in Stratagene Mx3005P qPCR thermocycler (Agilent Technologies, Palo Alto, CA, USA). After the first $10 \mathrm{~min}$ $\left(95^{\circ} \mathrm{C}\right), 40$ consecutive cycles were performed, with each cycle involving 15 -s reactions at $95^{\circ} \mathrm{C}$ and 60 -s reactions at $60^{\circ} \mathrm{C}$. Relative gene expression was calculated using the $\Delta \Delta \mathrm{Ct}$ 
method with phosphoglycerate kinase as the reference gene (Pgk1, cat. no. PPR56649C) (Qiagen, Hilden, Germany). The results were expressed as relative gene expression of the target gene vs. the reference genes $(P g k 1)$, with the control group calculated as 1 .

\subsection{Statistical Analysis}

Data obtained from the in vivo experiment and biochemical assays were analyzed statistically using Statistica v. 13.3 PL software (StatSoft Polska Sp. z o.o., Kraków, Poland). Gene expression and antioxidant potential values were analyzed by one-way analysis of variance (ANOVA). Before each analysis, the assumptions of ANOVA were verified. The normality of residual distribution was tested using the Shapiro-Wilk test, and the equality of variance using the Brown-Forsythe test. Data that did not meet the assumption of normality were logarithmized. Differences between the groups were assessed using the Tukey post hoc test. The results were considered statistically significant at $p<0.05$. GraphPad Prism (GraphPad Software 9.3.1) was used for creating all graphs. The experimental data from Fisher's linear discriminant analysis (LDA) were also analyzed in R statistical software v. 3.3.3 (www.rproject.org/, accessed on 20 December 2021; R: The R Project for Statistical Computing).

\section{Conclusions}

The present study revealed changes in the hippocampal concentrations of neurosteroids, as well as oxidative stress in the hippocampus, together with cognitive impairment, in rats exposed to silver. This may suggest that these mechanisms are responsible for the observed Ag neurotoxicity, which was strongly dependent on the coating material used on AgNPs and the Ag form. The study highlights that the effect of silver administered as $\mathrm{AgNPs}$ or as $\mathrm{Ag}^{+}$varies from that of $\mathrm{Ag}^{+}$released from AgNPs. Additionally, the results indicate that the mode of action of AgNPs with different types of coating is more similar to each other than to the action of $\mathrm{Ag}^{+}$ions. Thus, it seems that the toxicity of AgNPs cannot be explained solely by the release of $\mathrm{Ag}^{+}$ions.

Author Contributions: Conceptualization: K.D., M.W., J.G.-O. and M.K.; methodology: K.D. and J.W.; investigation: K.D. and J.W.; data curation: K.D. and W.G.; writing-original draft preparation: K.D. and W.G.; writing-review and editing: K.D, M.W., J.G.-O. and M.K.; visualization: K.D. and W.G.; supervision: M.K.; and funding acquisition: K.D. and M.W. All authors have read and agreed to the published version of the manuscript.

Funding: The authors acknowledge the financial support of the National Science Centre, Poland (grant MINIATURA I, 2017/01/X/NZ7/00648).

Institutional Review Board Statement: The animal experiment was approved by the First Warsaw Local Ethics Committee for Animal Experimentation (Resolution No. 788/2015 of 25 May 2015).

Informed Consent Statement: Not applicable.

Data Availability Statement: The data that support the findings of this study are available on request from the corresponding author (K.D.).

Conflicts of Interest: The authors declare no conflict of interest. The funders had no role in the design of the study; in the collection, analyses, or interpretation of data; in the writing of the manuscript, or in the decision to publish the results.

\section{References}

1. Akter, M.; Sikder, M.T.; Rahman, M.M.; Ullah, A.K.M.A.; Hossain, K.F.B.; Banik, S.; Hosokawa, T.; Saito, T.; Kurasaki, M. A systematic review on silver nanoparticles-induced cytotoxicity: Physicochemical properties and perspectives. J. Adv. Res. 2018, 9, 1-16. [CrossRef] [PubMed]

2. Consumer Products-The Nanodatabase. Available online: https://nanodb.dk/en/analysis/consumer-products/\#chartHashsection (accessed on 1 February 2021).

3. Yang, Y.; Westerhoff, P. Presence in, and release of, nanomaterials from consumer products. Adv. Exp. Med. Biol. 2014, 811, 1-17. [CrossRef] [PubMed]

4. Budama-Kilinc, Y.; Cakir-Koc, R.; Zorlu, T.; Ozdemir, B.; Karavelioglu, Z.; Egil, A.C.; Kecel-Gunduz, S. Assessment of Nanotoxicity and Safety Profiles of Silver Nanoparticles. Silver Nanopart.-Fabr. Charact. Appl. 2018, 75645. [CrossRef] 
5. Abdelkhaliq, A.; van der Zande, M.; Undas, A.K.; Peters, R.J.B.; Bouwmeester, H. Impact of in vitro digestion on gastrointestinal fate and uptake of silver nanoparticles with different surface modifications. Nanotoxicology 2020, 14, 111-126. [CrossRef] [PubMed]

6. $\quad$ Chen, R.J.; Huang, C.C.; Pranata, R.; Lee, Y.H.; Chen, Y.Y.; Wu, Y.H.; Wang, Y.J. Modulation of innate immune toxicity by silver nanoparticle exposure and the preventive effects of pterostilbene. Int. J. Mol. Sci. 2021, 22, 2536. [CrossRef] [PubMed]

7. Dubey, P.; Matai, I.; Kumar, S.U.; Sachdev, A.; Bhushan, B.; Gopinath, P. Perturbation of cellular mechanistic system by silver nanoparticle toxicity: Cytotoxic, genotoxic and epigenetic potentials. Adv. Colloid Interface Sci. 2015, 221, 4-21. [CrossRef] [PubMed]

8. Krawczyńska, A.; Dziendzikowska, K.; Gromadzka-Ostrowska, J.; Lankoff, A.; Herman, A.P.; Oczkowski, M.; Królikowski, T.; Wilczak, J.; Wojewódzka, M.; Kruszewski, M. Silver and titanium dioxide nanoparticles alter oxidative/inflammatory response and renin-angiotensin system in brain. Food Chem. Toxicol. 2015, 85, 96-105. [CrossRef]

9. Panzarini, E.; Mariano, S.; Carata, E.; Mura, F.; Rossi, M.; Dini, L. Intracellular transport of silver and gold nanoparticles and biological responses: An update. Int. J. Mol. Sci. 2018, 19, 1305. [CrossRef]

10. Liu, J.; Jiang, G. Silver Nanoparticles in the Environment; Springer: Berlin/Heidelberg, Germany, 2015; pp. 1-152. [CrossRef]

11. Strużyńska, L.; Skalska, J. Mechanisms Underlying Neurotoxicity of Silver Nanoparticles. Adv. Exp. Med. Biol. 2018, 1048, 227-250. [CrossRef]

12. Dziendzikowska, K.; Krawczyńska, A.; Oczkowski, M.; Królikowski, T.; Brzóska, K.; Lankoff, A.; Dziendzikowski, M.; Stępkowski, T.; Kruszewski, M.; Gromadzka-Ostrowska, J. Progressive effects of silver nanoparticles on hormonal regulation of reproduction in male rats. Toxicol. Appl. Pharmacol. 2016, 313, 35-46. [CrossRef]

13. Rezvani, E.; Rafferty, A.; McGuinness, C.; Kennedy, J. Adverse effects of nanosilver on human health and the environment. Acta Biomater. 2019, 94, 145-159. [CrossRef] [PubMed]

14. Antsiferova, A.; Buzulukov, Y.; Demin, V.; Kashkarov, P.; Kovalchuk, M.; Petritskaya, E. Extremely low level of Ag nanoparticle excretion from mice brain in in vivo experiments. IOP Conf. Ser. Mater. Sci. Eng. 2015, 98, 012003. [CrossRef]

15. Greish, K.; Alqahtani, A.A.; Alotaibi, A.F.; Abdulla, A.M.; Bukelly, A.T.; Alsobyani, F.M.; Alharbi, G.H.; Alkiyumi, I.S.; Aldawish, M.M.; Alshahrani, T.F.; et al. The effect of silver nanoparticles on learning, memory and social interaction in balb/c mice. Int. J. Environ. Res. Public Health 2019, 16, 148. [CrossRef] [PubMed]

16. Węsierska, M.; Dziendzikowska, K.; Gromadzka-Ostrowska, J.; Dudek, J.; Polkowska-Motrenko, H.; Audinot, J.N.; Gutleb, A.C.; Lankoff, A.; Kruszewski, M. Silver ions are responsible for memory impairment induced by oral administration of silver nanoparticles. Toxicol. Lett. 2018, 290, 133-144. [CrossRef]

17. Kruszewski, M.; Grzelak, A. Nanoparticle toxicity and reactive species: An overview. Toxicology 2021, 11-21. [CrossRef]

18. Huang, C.L.; Hsiao, I.L.; Lin, H.C.; Wang, C.F.; Huang, Y.J.; Chuang, C.Y. Silver nanoparticles affect on gene expression of inflammatory and neurodegenerative responses in mouse brain neural cells. Environ. Res. 2015, 136, 253-263. [CrossRef]

19. Khan, A.M.; Korzeniowska, B.; Gorshkov, V.; Tahir, M.; Schrøder, H.; Skytte, L.; Rasmussen, K.L.; Khandige, S.; Møller-Jensen, J.; Kjeldsen, F. Silver nanoparticle-induced expression of proteins related to oxidative stress and neurodegeneration in an in vitro human blood-brain barrier model. Nanotoxicology 2019, 13, 221-239. [CrossRef]

20. Ahsan, S.M.; Rao, C.M.; Ahmad, M.F. Nanoparticle-protein interaction: The significance and role of protein corona. Adv. Exp. Med. Biol. 2018, 1048, 175-198. [CrossRef]

21. Tortella, G.R.; Rubilar, O.; Durán, N.; Diez, M.C.; Martínez, M.; Parada, J.; Seabra, A.B. Silver nanoparticles: Toxicity in model organisms as an overview of its hazard for human health and the environment. J. Hazard. Mater. 2020, 390, 121974. [CrossRef]

22. Báez, D.F.; Gallardo-Toledo, E.; Oyarzún, M.P.; Araya, E.; Kogan, M.J. The influence of size and chemical composition of silver and gold nanoparticles on in vivo toxicity with potential applications to central nervous system diseases. Int. J. Nanomed. 2021, 16, 2187-2201. [CrossRef]

23. Recordati, C.; De Maglie, M.; Cella, C.; Argentiere, S.; Paltrinieri, S.; Bianchessi, S.; Losa, M.; Fiordaliso, F.; Corbelli, A.; Milite, G.; et al. Repeated oral administration of low doses of silver in mice: Tissue distribution and effects on central nervous system. Part. Fibre Toxicol. 2021, 18, 1-18. [CrossRef] [PubMed]

24. Dziendzikowska, K.; Węsierska, M.; Gromadzka-Ostrowska, J.; Wilczak, J.; Oczkowski, M.; Męczyńska-Wielgosz, S.; Kruszewski, M. Silver Nanoparticles Impair Cognitive Functions and Modify the Hippocampal Level of Neurotransmitters in a CoatingDependent Manner. Int. J. Mol. Sci. 2021, 22, 12706. [CrossRef]

25. Wang, M.; Li, S.; Chen, Z.; Zhu, J.; Hao, W.; Jia, G.; Chen, W.; Zheng, Y.; Qu, W.; Liu, Y. Safety assessment of nanoparticles in food: Current status and prospective. Nano Today 2021, 39, 101169. [CrossRef]

26. Cunningham, B.; Engstrom, A.E.; Harper, B.J.; Harper, S.L.; Mackiewicz, M.R. Silver nanoparticles stable to oxidation and silver ion release show size-dependent toxicity in vivo. Nanomaterials 2021, 11, 1516. [CrossRef] [PubMed]

27. Gamucci, O.; Bertero, A.; Gagliardi, M.; Bardi, G. Biomedical nanoparticles: Overview of their surface immune-compatibility. Coatings 2014, 4, 139-159. [CrossRef]

28. Chang, X.; Li, J.; Niu, S.; Xue, Y.; Tang, M. Neurotoxicity of metal-containing nanoparticles and implications in glial cells. J. Appl. Toxicol. 2021, 41, 65-81. [CrossRef]

29. Kim, K.J.; Sung, W.S.; Suh, B.K.; Moon, S.K.; Choi, J.S.; Kim, J.G.; Lee, D.G. Antifungal activity and mode of action of silver nano-particles on Candida albicans. BioMetals 2009, 22, 235-242. [CrossRef]

30. Talarska, P.; Boruczkowski, M.; Żurawski, J. Current knowledge of silver and gold nanoparticles in laboratory researchApplication, toxicity, cellular uptake. Nanomaterials 2021, 11, 2454. [CrossRef] 
31. Smith, J.A.; Park, S.; Krause, J.S.; Banik, N.L. Oxidative stress, DNA damage, and the telomeric complex as therapeutic targets in acute neurodegeneration. Neurochem. Int. 2013, 62, 764-775. [CrossRef]

32. Feng, X.; Chen, A.; Zhang, Y.; Wang, J.; Shao, L.; Wei, L. Central nervous system toxicity of metallic nanoparticles. Int. J. Nanomed. 2015, 10, 4321-4340. [CrossRef]

33. Janzadeh, A.; Behroozi, Z.; Janzadeh, N.; Arzani, H.; Tanha, K. Neurotoxicity of silver nanoparticles in the animal brain: A systematic review and meta-analysis. Forensic Toxicol. 2022, 40, 49-63. [CrossRef]

34. Skalska, J.; Dąbrowska-Bouta, B.; Strużyńska, L. Oxidative stress in rat brain but not in liver following oral administration of a low dose of nanoparticulate silver. Food Chem. Toxicol. 2016, 97, 307-315. [CrossRef] [PubMed]

35. Dayem, A.A.; Lee, S.B.; Choi, H.Y.; Cho, S.G. Silver nanoparticles: Two-faced neuronal differentiation-inducing material in neuroblastoma (SH-SY5Y) cells. Int. J. Mol. Sci. 2018, 19, 1470. [CrossRef]

36. Sun, C.; Yin, N.; Wen, R.; Liu, W.; Jia, Y.; Hu, L.; Zhou, Q.; Jiang, G. Silver nanoparticles induced neurotoxicity through oxidative stress in rat cerebral astrocytes is distinct from the effects of silver ions. Neurotoxicology 2016, 52, 210-221. [CrossRef] [PubMed]

37. Dziendzikowska, K.; Gromadzka-Ostrowska, J.; Lankoff, A.; Oczkowski, M.; Krawczyńska, A.; Chwastowska, J.; Sadowska-Bratek, M.; Chajduk, E.; Wojewódzka, M.; Dušinská, M.; et al. Time-dependent biodistribution and excretion of silver nanoparticles in male Wistar rats. J. Appl. Toxicol. 2012, 32, 920-928. [CrossRef] [PubMed]

38. Valand, R.; Magnusson, P.; Dziendzikowska, K.; Gajewska, M.; Wilczak, J.; Oczkowski, M.; Kamola, D.; Królikowski, T.; Kruszewski, M.; Lankoff, A.; et al. Gene expression changes in rat brain regions after 7- and 28 days inhalation exposure to exhaust emissions from 1st and 2nd generation biodiesel fuels-The FuelHealth project. Inhal. Toxicol. 2018, 30, 299-312. [CrossRef]

39. Dănilă, O.O.; Berghian, A.S.; Dionisie, V.; Gheban, D.; Olteanu, D.; Tabaran, F.; Baldea, I.; Katona, G.; Moldovan, B.; Clichici, S.; et al. The effects of silver nanoparticles on behavior, apoptosis and nitro-oxidative stress in offspring Wistar rats. Nanomedicine 2017, 12, 1455-1473. [CrossRef]

40. Yousef, M.I.; Abuzreda, A.A.; Kamel, M.A.E.-N. Neurotoxicity and inflammation induced by individual and combined exposure to iron oxide nanoparticles and silver nanoparticles. J. Taibah Univ. Sci. 2019, 13, 570-578. [CrossRef]

41. Chen, R.; Zhao, L.; Bai, R.; Liu, Y.; Han, L.; Xu, Z.; Chen, F.; Autrup, H.; Long, D.; Chen, C. Silver nanoparticles induced oxidative and endoplasmic reticulum stresses in mouse tissues: Implications for the development of acute toxicity after intravenous administration. Toxicol. Res. 2016, 5, 602-608. [CrossRef]

42. Dąbrowska-Bouta, B.; Sulkowski, G.; Strużyński, W.; Strużyńska, L. Prolonged Exposure to Silver Nanoparticles Results in Oxidative Stress in Cerebral Myelin. Neurotox. Res. 2019, 35, 495-504. [CrossRef]

43. Davenport, L.L.; Hsieh, H.; Eppert, B.L.; Carreira, V.S.; Krishan, M.; Ingle, T.; Howard, P.C.; Williams, M.T.; Vorhees, C.V.; Genter, M.B. Systemic and behavioral effects of intranasal administration of silver nanoparticles. Neurotoxicol. Teratol. 2015, 51, 68-76. [CrossRef] [PubMed]

44. Attia, A.; Ramadan, H.; ElMazoudy, R.; Abdelnaser, A. Disruption of brain conductivity and permittivity and neurotransmitters induced by citrate-coated silver nanoparticles in male rats. Environ. Sci. Pollut. Res. 2021, 28, 38332-38347. [CrossRef] [PubMed]

45. Opris, R.V.; Toma, V.; Baciu, A.M.; Moldovan, R.; Dume, B.; Berghian-sevastre, A.; Moldovan, B.; Clichici, S.; David, L.; Filip, G.A.; et al. Neurobehavioral and Ultrastructural Changes Induced by Phytosynthesized Silver-Nanoparticle Toxicity in an In Vivo Rat Model. Nanomaterials 2022, 12, 58. [CrossRef] [PubMed]

46. Repar, N.; Li, H.; Aguilar, J.S.; Li, Q.Q.; Drobne, D.; Hong, Y. Silver nanoparticles induce neurotoxicity in a human embryonic stem cell-derived neuron and astrocyte network. Nanotoxicology 2018, 12, 104-116. [CrossRef] [PubMed]

47. Pfrieger, F.W.; Ungerer, N. Cholesterol metabolism in neurons and astrocytes. Prog. Lipid Res. 2011, 50, 357-371. [CrossRef]

48. Reddy, D.S. Neurosteroids. Endogenous role in the human brain and therapeutic potentials. Prog. Brain Res. 2010, $186,113-137$. [CrossRef]

49. Papadopoulos, V.; Miller, W.L. Role of mitochondria in steroidogenesis. Best Pract. Res. Clin. Endocrinol. Metab. 2012, 26, 771-790. [CrossRef]

50. Fokidis, H.B.; Adomat, H.H.; Kharmate, G.; Hosseini-Beheshti, E.; Guns, E.S.; Soma, K.K. Regulation of local steroidogenesis in the brain and in prostate cancer: Lessons learned from interdisciplinary collaboration. Front. Neuroendocrinol. 2015, 36, 108-129. [CrossRef]

51. Rammouz, G.; Lecanu, L.; Papadopoulos, V.; Vaudry, H.; Vazquez-Martinez, R. Oxidative stress-mediated brain dehydroepiandrosterone (DHEA) formation in Alzheimer's disease diagnosis. Front. Endocrinol. 2011, 2, 69. [CrossRef]

52. Gautam, D.K.; Misro, M.M.; Chaki, S.P.; Sehgal, N. $\mathrm{H}_{2} \mathrm{O}_{2}$ at physiological concentrations modulates Leydig cell function inducing oxidative stress and apoptosis. Apoptosis 2006, 11, 39-46. [CrossRef]

53. Hadrup, N.; Loeschner, K.; Mortensen, A.; Sharma, A.K.; Qvortrup, K.; Larsen, E.H.; Lam, H.R. The similar neurotoxic effects of nanoparticulate and ionic silver in vivo and in vitro. Neurotoxicology 2012, 33, 416-423. [CrossRef] [PubMed]

54. Wei, L.; Tang, J.; Zhang, Z.; Chen, Y.; Zhou, G.; Xi, T. Investigation of the cytotoxicity mechanism of silver nanoparticles in vitro. Biomed. Mater. 2010, 5, 044103. [CrossRef] [PubMed]

55. De Matteis, V.; Malvindi, M.A.; Galeone, A.; Brunetti, V.; De Luca, E.; Kote, S.; Kshirsagar, P.; Sabella, S.; Bardi, G.; Pompa, P.P. Negligible particle-specific toxicity mechanism of silver nanoparticles: The role of $\mathrm{Ag}+$ ion release in the cytosol. Nanomed. Nanotechnol. Biol. Med. 2015, 11, 731-739. [CrossRef] [PubMed] 
56. Lyu, Z.; Ghoshdastidar, S.; Rekha, K.R.; Suresh, D.; Mao, J.; Bivens, N.; Kannan, R.; Joshi, T.; Rosenfeld, C.S.; Upendran, A. Developmental exposure to silver nanoparticles leads to long term gut dysbiosis and neurobehavioral alterations. Sci. Rep. 2021, 11, 1-14. [CrossRef] [PubMed]

57. Trudeau, V.L.; Vaudry, D.; Xifró, X.; Farb, D.H.; Ratner, M.H.; Kumaresan, V. Neurosteroid Actions in Memory and Neurologic/Neuropsychiatric Disorders. Front. Endocrinol. 2019, 10, 169. [CrossRef]

58. Pan, X.; Wu, X.; Kaminga, A.C.; Wen, S.W.; Liu, A. Dehydroepiandrosterone and Dehydroepiandrosterone Sulfate in Alzheimer's Disease: A Systematic Review and Meta-Analysis. Front. Aging Neurosci. 2019, 11, 61. [CrossRef]

59. Safiulina, D.; Peet, N.; Seppet, E.; Zharkovsky, A.; Kaasik, A. Dehydroepiandrosterone inhibits complex I of the mitochondrial respiratory chain and is neurotoxic in vitro and in vivo at high concentrations. Toxicol. Sci. 2006, 93, 348-356. [CrossRef]

60. Saloniemi, T.; Jokela, H.; Strauss, L.; Pakarinen, P.; Poutanen, M. The diversity of sex steroid action: Novel functions of hydroxysteroid $(17 \beta)$ dehydrogenases as revealed by genetically modified mouse models. J. Endocrinol. 2012, 212, 27-40. [CrossRef]

61. Vinklarova, L.; Schmidt, M.; Benek, O.; Kuca, K.; Gunn-Moore, F.; Musilek, K. Friend or enemy? Review of $17 \beta-H S D 10$ and its role in human health or disease. J. Neurochem. 2020, 155, 231-249. [CrossRef]

62. Yang, S.Y.; He, X.Y.; Miller, D. HSD17B10: A gene involved in cognitive function through metabolism of isoleucine and neuroactive steroids. Mol. Genet. Metab. 2007, 92, 36-42. [CrossRef]

63. Cueva, C.; Gil-Sánchez, I.; Tamargo, A.; Miralles, B.; Crespo, J.; Bartolomé, B.; Moreno-Arribas, M.V. Gastrointestinal digestion of food-use silver nanoparticles in the dynamic SIMulator of the GastroIntestinal tract (simgi $\left.{ }^{\circledR}\right)$. Impact on human gut microbiota. Food Chem. Toxicol. 2019, 132, 110657. [CrossRef] [PubMed]

64. Laloux, L.; Kastrati, D.; Cambier, S.; Gutleb, A.C.; Schneider, Y.J. The Food Matrix and the Gastrointestinal Fluids Alter the Features of Silver Nanoparticles. Small 2020, 16, 1-11. [CrossRef] [PubMed]

65. Meczyńska-Wielgosz, S.; Wojewódzka, M.; Matysiak-Kucharek, M.; Czajka, M.; Jodlowska-Jedrych, B.; Kruszewski, M.; KapkaSkrzypczak, L. Susceptibility of HepG2 cells to silver nanoparticles in combination with other metal/metal oxide nanoparticles. Materials 2020, 13, 2221. [CrossRef] [PubMed]

66. Lankoff, A.; Sandberg, W.J.; Wegierek-Ciuk, A.; Lisowska, H.; Refsnes, M.; Sartowska, B.; Schwarze, P.E.; Meczynska-Wielgosz, S.; Wojewodzka, M.; Kruszewski, M. The effect of agglomeration state of silver and titanium dioxide nanoparticles on cellular response of HepG2, A549 and THP-1 cells. Toxicol. Lett. 2012, 208, 197-213. [CrossRef] [PubMed]

67. Ohkawa, H.; Ohishi, N.; Yagi, K. Assay for lipid peroxides in animal tissues by thiobarbituric acid reaction. Anal. Biochem. 1979, 95, 351-358. [CrossRef] 